\title{
Hypoxia promotes a perinatal-like progenitor state in the adult murine epicardium
}

Running title: Epicardial progenitors depend on hypoxia

Angeliqua Sayed, $\mathrm{PhD}^{1}$; Szimonetta Turoczi, Ms¹; Francisca Soares-da-Silva, $\mathrm{PhD}^{3}$;

Giovanna Marazzi, MD¹; Jean-Sébastien Hulot, MD, $\mathrm{PhD}^{1,2}$; David Sassoon, $\mathrm{PhD}^{1}$ and Mariana Valente, $\mathrm{PhD}^{1}$

Affiliations:

${ }^{1}$ Université de Paris, INSERM- U970, PARCC, F-75006 Paris, France;

${ }^{2}$ CIC1418 and DMU CARTE, AP-HP, Hôpital Européen Georges-Pompidou, F-75015, Paris, France;

${ }^{3}$ Lymphocytes and Immunity Unit, Immunology Department, Institut National de la Santé et de la Recherche Médicale U1223, Institut Pasteur, Paris, France.

Corresponding author:

Dr. David Sassoon

Email: david.a.sassoon@gmail.com 


\begin{abstract}
The epicardium is a reservoir of progenitors that give rise to coronary vasculature and stroma during development and mediates cardiac vascular repair in lower vertebrates. However, its role as a source of progenitors in the adult mammalian heart remains unclear due to lack of clear lineage markers and single-cell culture systems to elucidate epicardial progeny cell fate. We found that in vivo exposure of mice to physiological hypoxia induced adult epicardial cells to re-enter the cell cycle and to express a subset of developmental genes. Multiplex transcriptional profiling revealed a lineage relationship between epicardial cells and smooth muscle, stromal, and endothelial fates, and that physiological hypoxia promoted an endothelial cell fate. In vitro analyses of purified epicardial cells showed that cell growth and subsequent differentiation is dependent upon hypoxia, and that resident epicardial cells retain progenitor identity in the adult mammalian heart with self-renewal and multilineage differentiation potential. These results point to a source of progenitor cells in the adult heart that can promote heart revascularization, providing an invaluable in vitro model for further studies.
\end{abstract}

Key Words: Hypoxia priming, adult epicardial progenitors, in vitro epicardial system, multipotency stimulation, perinatal progenitor potential. 


\section{Introduction}

The epicardium gives rise to epicardial-derived cells (EPDCs) located in the subepicardial layer that migrate into the myocardium to give rise to interstitial cells, perivascular stroma and smooth muscle cells during development and early postnatal life(Cai et al, 2008; Dettman et al, 1998; Gittenberger-de Groot et al, 1998; Mikawa \& Gourdie, 1996; Perez-Pomares et al, 1997; Wessels et al, 2012; Zhou et al, 2008). The contribution of the epicardium to endothelial cells is controversial in mammals(Cai et al., 2008; Duim et al, 2015; Merki et al, 2005; PerezPomares et al, 2002; Red-Horse et al, 2010; Tian et al, 2013; Zhou et al., 2008) in part due to the small number of epicardial cells in the heart and a lack of suitable genetic cell fate models(Christoffels et al, 2009; Duim et al., 2015; Duim et al, 2016; Rudat \& Kispert, 2012). In addition, methodologies available to functionally study epicardial cells are limited to explant cultures that do not allow for definitive lineage and clonal analyses(Bax et al, 2019; Cao \& Poss, 2016; Kim et al, 2012; Ramesh et al, 2016; Smart et al, 2007; Tran et al, 2016). Opposite to mammals, the multilineage capacity of the epicardium, including a contribution to endothelial cells, is well established in several non-mammalian vertebrate models where the adult epicardium gives rise directly to vasculature following injury(Dettman et al., 1998; Manner, 1993; Merki et al., 2005; Mikawa \& Gourdie, 1996; Olivey et al, 2004; Poss et al, 2002).

In contrast to the adult, the neonatal heart is able to functionally recover following injury(Haubner et al, 2012; Porrello et al, 2011; Sampaio-Pinto et al, 2018). The perinatal heart is known to be hypoxic due to an immature vasculature structure(Nanka et al, 2006; Olivetti et al, 1980; Tian et al., 2013; Tian et al, 2015; Tomanek, 1996) and other studies have shown that many progenitors in different tissues are present in hypoxic niches(Huang et al, 2018). These observations directly bear upon potential therapeutic avenues of discovery since it was reported recently that stepwise exposure of mice to hypoxia leads to a marked improvement in functional recovery of the heart following ischemia(Nakada et al, 2017). The 
degree of progenitor involvement in response to hypoxia in the adult remains unclear. The adult epicardium consists of progenitors and constitutes a physiological hypoxic niche due to the low capillary density and the constitutive expression of hypoxia inducible factor 1 alpha (HIF-1a)(Kocabas et al, 2012).

While these findings show that hypoxia and signaling effectors in a hypoxic response play a role in epicardial development and cardiac injury (Hesse et al, 2021a; Hesse et al, 2021b; Jing et al, 2016; Kocabas et al., 2012; Tao et al, 2018), it remains unknown whether there is a stimulation (priming) of the adult epicardium after in vivo hypoxia exposure. In addition, how prospectively isolated single epicardial cells behave is unknown, since efforts to date have been hampered by the inability to maintain and expand these cells in culture. Consequently, the functional analysis of epicardial cells, at the single cell level, in respond to hypoxia has remained largely unaddressed. We therefore tested whether hypoxia regulates the epicardial progenitor competence. As a first step, we established a sorting strategy based upon known surface proteins together with a reporter mouse line for Peg3/Pw1 (hereinafter referred to as $P w 1) . P w 1$ is expressed in a wide array of progenitor cells during development and in the adult, and is linked to the stem cell capacity of selfrenewal as well as differentiation into specific tissue lineages(Besson et al, 2011; Kuroiwa et al, 1996; Mitchell et al, 2010). We demonstrated previously that PW1 is expressed in a subset of stromal cells in the adult heart, which generates pro-fibrotic cells in response to injury(Bouvet et al, 2020; Yaniz-Galende et al, 2017). However, PW1 expression had not been examined during early postnatal development when rapid heart growth and differentiation takes place. We show here that PW1 is expressed in the Gp38+epicardium (Mahtab et al, 2008; Smart et al, 2011; Valente et al, 2019) from development throughout adult life, consistent with progenitor capacity for this compartment(Cai et al., 2008; Dettman et al., 1998; Gittenberger-de Groot et al., 1998; Mikawa \& Gourdie, 1996; Perez-Pomares et al., 1997; Wessels et al., 2012; Zhou et al., 2008). We also show that hypoxia induces an increase 
in the number of PW1 expressing cells in the ${\mathrm{Gp} 38^{+} \text {epicardium and PDGFRa }}^{+}$ subepicardium. Multiplex transcriptional profiling revealed that Gp38+PW1+ epicardial cells upregulate endothelial lineage-associated genes in response to hypoxia similar to what is found in the epicardium at birth. Lastly, while previous studies relied on explants cultures, we show here that freshly purified $\mathrm{Gp} 38^{+} \mathrm{PW} 1^{+}$epicardial cells display robust clonogenicity, self-renewal, and multipotency uniquely under hypoxic conditions, whereas they do not grow under normoxic conditions. Adult $\mathrm{Gp} 38^{+} \mathrm{PW} 1^{+}$epicardial cells from physiological hypoxiaprimed mice displayed a marked increase in their competence to grow and differentiate in vitro similar to what is observed with the neonatal epicardial cells. Taken together, our data support the hypothesis that the adult mammalian epicardium is a niche for resident $\mathrm{Gp} 38^{+} \mathrm{PW} 1^{+}$progenitors and that exposure to hypoxia promotes robust progenitor activity similar to neonatal epicardium, including the activation of endothelial cell fate.

\section{Results}

\section{Chronic physiological hypoxia exposure in the adult heart activates a developmental} profile in the epicardial and subepicardial layers

Previous studies have shown that the epicardium is hypoxic (Kocabas et al., 2012) and contains multipotent progenitors (Acharya et al, 2012; Smart et al., 2011; Wessels \& PérezPomares, 2004; Winter \& Gittenberger-de Groot, 2007). While there are conflicting reports regarding epicardial progenitor potential in the adult mammalian heart, it is well established that the epicardium has a pronounced progenitor capacity during mammalian development, corresponding to a hypoxic state in both the epicardium and underlying cell layers (Guimaraes-Camboa et al, 2015; Sugishita et al, 2004; Tomanek et al, 2003; Wikenheiser et al, 2006). This raised the possibility that hypoxia directly regulates epicardial progenitors and is required for progenitor function. To explore the role of hypoxia, we placed adult mice 
into a hypoxic chamber at $10 \% \mathrm{O}_{2}$ for 2 weeks (Figure $1 \mathrm{~A}$ ), which is well tolerated and sufficient to induce overt physiological changes, including cardiac enlargement coupled with a reduced overall body weight, as reported by others(Nakada et al., 2017) (Figure I-A-B in the Supplement). We used pimonidazole as a surrogate marker for hypoxic cells(Krohn et al, 2008; Nunn et al, 1995). Pimonidazole staining in the epicardium and subepicardium as well as a stronger staining in the myocardial interstitium confirmed that the experimental conditions used were sufficient to induce generalized hypoxia in the heart (Figure 1B-C) and we noted that pimonidazole labeling intensity was similar in to that detected at P0 (Figure 1C).

Histological analyses revealed a striking increase in the thickness of the epicardial and subepicardial layers in response to hypoxia (Figure 1D-E) coupled with an increase in nuclei number (Figure 1F), as observed during development (Figure I-D in the Supplement). Consistent with these observations, we detected a marked increase in cell proliferation in the subepicardial cells (PDGFRa ${ }^{+}$, Figure $1 \mathrm{G}-\mathrm{H}$ ) in response to hypoxia using the cell proliferation marker phosphorylated histone $\mathrm{H} 3(\mathrm{pH})$, suggesting that cell proliferation contributes to the increased thickness following hypoxia in the subepicardial layer (Figure 1D-F). While proliferative cells are present at low levels in the adult heart(Eschenhagen et al, 2017; Soonpaa et al, 1996) our results show that chronic exposure to hypoxia activates epicardial and subepicardial cell proliferation. Previous studies have shown that proliferation of epicardial/subepicardial cells is a feature of embryonic development(Cai et al., 2008; Dettman et al., 1998; Gittenberger-de Groot et al., 1998; Wessels \& Pérez-Pomares, 2004; Zhou et al., 2008), therefore we tested whether other epicardial developmental markers were induced concomitant with cell proliferation. One such marker, WT1, is expressed in the epicardial and subepicardial compartments during embryonic heart development (Cossette \& Misra, 2011; Duim et al., 2016; Manner et al, 2005; Zhou et al., 2008). We observed a marked induction of WT1 expression in the epicardium and subepicardium 
(Figure 1I-J). Taken together, our results show that physiological hypoxia activates both cell proliferation and WT1 expression in the adult that are hallmarks of early epicardial/pericardial development.

\section{PW1 is expressed at high levels in the epicardium and subepicardium throughout life}

In order to isolate epicardial and subepicardial cells to assess their progenitor potential profile, we established a precise gating strategy to purify the different cardiac populations. We used antibodies to multiple cell surface proteins combined with a reporter mouse model for the expression of the adult progenitor cell marker Peg3/Pw1 (hereinafter referred to as Pw1)(Besson et al., 2011; Kuroiwa et al., 1996; Mitchell et al., 2010). Endothelial and stromal cells were defined by the expression of platelet endothelial cell adhesion molecule 1 $\left(\mathrm{PECAM}-1^{+}\right.$or $\left.\mathrm{CD} 31^{+}\right)$and platelet-derived growth factor receptor alpha (PDGFR or CD140a), respectively. Hematopoietic cells were excluded by the combination of CD45, CD11b and Ter119 antibodies (Figure IIA in the Supplement). To define epicardial cells, we used an antibody to the surface glycoprotein 38 (Gp38 or podoplanin, Figure IIA in the Supplement), which has been shown to be expressed in the epicardial layer during development(Mahtab et al., 2008; Valente et al., 2019) as well as in the adult(Smart et al., 2011; Valente et al., 2019). While Gp38 is expressed in other cardiac cells population (hematopoietic, endothelial and stromal cells)(Hou et al, 2010; Stellato et al, 2019; Weninger et al, 1999), we excluded these cell lineages in our sorting strategy (Figure 2A, Figure IIA-B in the Supplement). We found $\sim 70 \%$ of the Gp38-expressing cells co-expressed the $P w 1$ reporter gene at P0 and the $P w 1$ reporter gene co-expression was maintained in the adult ( $\approx 50 \%$, Figure 2B). We observed that PDGFRa ${ }^{+}$cells (subepicardial/stromal cells) expressed the $P w 1$ reporter gene at all stages at high levels $(\approx 80 \%$ and $60 \%$, respectively, Figure 2B), whereas CD31+ cells (endothelial cells) underwent a sharp decline in PW1 expression during postnatal life ( $\mathrm{PO} \approx 45 \%$ vs. adult $\approx 10 \%$, Figure $2 \mathrm{~B}$ ). Flow cytometry 
analyses revealed that while the overall frequency of $\mathrm{PW}^{+}$cells increases in response to

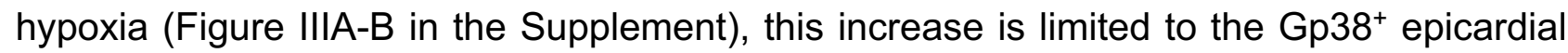
and $\mathrm{CD} 31^{+}$endothelial cells, whereas stromal cells do not show a significant change (Figure 2B). Immunostaining confirmed PW1 protein expression in the epicardium and subepicardium and showed that $\mathrm{PW}^{+}$cells co-expressed Gp38 in the epicardium and PDGFRa in the subepicardium (Figure 2C-D). Although an overall 4-fold decrease of PW1 expression was observed between $\mathrm{PO}$ and adult in the epicardium $\left(\mathrm{Gp} 38^{+}\right)$and subepicardium (PDGFRa ${ }^{+}$), PW1 expression remained markedly higher in these layers (Figure 2E). These results also reveal that subepicardial PDGFR ${ }^{+}$cells respond to hypoxia through an increase in PW1 expression, however the stromal PW1 ${ }^{+} \mathrm{PDGFR} \alpha^{+}$compartment present in the cardiac interstitium do not show a significant response as measured by flow cytometry (Figure IIIC in the Supplement). We propose that the marked increase in PW1 expression in PDGFRa ${ }^{+}$subepicardial cells is not observed using flow cytometry since the $\mathrm{PDGFRa}^{+}$subepicardial cells constitute a minor population as compared to PDGFRa ${ }^{+}$ stromal cells which cannot be discriminated between the two compartments using the available cell surface markers.

We and others have shown that Pw1 participates in multiple cell stress pathways(Feng et al, 2008; Kohda et al, 2001; Relaix et al, 2000; Relaix et al, 1998; Schwarzkopf et al, 2006) and regulates glucose metabolism(Correra et al, 2018). We therefore explored whether PW1 expression is regulated by hypoxia that is known to trigger cell stress and regulate glucose metabolism(Giaccia et al, 2004). We confirmed that hypoxic cells are restricted to the epicardial and subepicardial layers in the adult (Figure 1B) and express PW1 (Figure 2F). Moreover, the developmental epicardial transcription factor WT1 was co-expressed with the

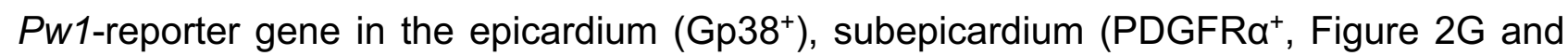
Figure IIID in the Supplement), indicating that the activated epicardial and subepicardial cells also co-expressed Pw1. Taken together, our data show that PW1 expression 
decreases during postnatal life in the ventricles, but levels remain elevated in the epicardial and subepicardial compartments. This observation is particularly relevant since epicardial and subepicardial layers have been shown to be a reservoir of cardiovascular progenitors during development(Cai et al., 2008; Dettman et al., 1998; Gittenberger-de Groot et al., 1998; Wessels \& Pérez-Pomares, 2004; Zhou et al., 2008) and that PW1 is expressed by multiple progenitor cell types in the adult(Besson et al., 2011; Kuroiwa et al., 1996; Mitchell et al., 2010).

\section{Epicardial cells express a progenitor/multipotent transcriptional profile in response}

\section{to hypoxia}

To better characterize the epicardial response to hypoxia and define how the adult epicardium compares to the perinatal state, we designed a multiplex qPCR panel of known genes corresponding to the major proposed epicardial lineages as well as to genes that respond to oxygen metabolism in freshly sorted cardiac populations (Table I in the Supplement). Unsupervised hierarchical clustering (Figure IV-A in the Supplement) and UMAP1 vs. UMAP2 (Uniform Manifold Approximation and Projection, Figure IV-B in the Supplement) at population level segregated the main cardiac populations in: CD $31^{+}$ endothelial cells irrespective of the time-point or hypoxia exposure (cluster I); developing Gp38+ epicardial cells (E17.5 and P0, cluster II); the majority of PDGFRa ${ }^{+}$cells assembled in two adjacent clusters (clusters III and IV), which differ from each other due to high expression of Cdh5 and lower levels of Col1a1, Tcf21 and Postn in the cluster of hypoxia-

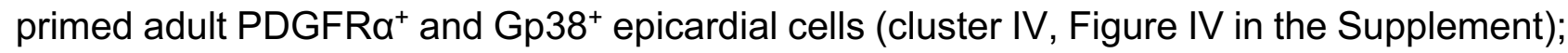

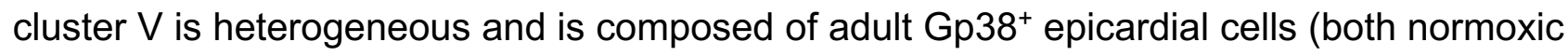
and hypoxic) together with hypoxia-primed PDGFRa ${ }^{+}$and $\mathrm{CD} 31^{+}$cells (Figure IV in the Supplement). While these results validate our approach to discriminate the main cardiac

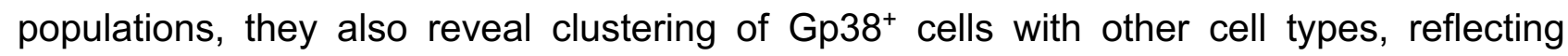


heterogeneity of epicardial cells and the transcriptional profile overlap of hypoxia exposed epicardial, stromal, and endothelial cells (Figure IV in the Supplement).

We analyzed 382 cells at the single cell level, and further confirmed our results observed at the population level (Figure IV in the Supplement) by unsupervised hierarchical clustering (heat-map, Figure V-A in the Supplement) and tSNE projection (t-Distributed Stochastic Neighbor Embedding, Figure V-B in the Supplement). Freshly sorted Gp38+epicardial cells are highly heterogeneous and were split in the four obtained clusters (Figure $\mathrm{V}$ in the Supplement). Further single cell transcriptional analysis of the Gp38+ epicardial population (168 cells) revealed unique transcriptional signatures of the different epicardial subsets (Figure 3A). Epicardial-associated genes (Wt1, Gpm6a, Bnc1 and Tbx18) are highly expressed during development (P0 cluster I, III and IV) and after injury(Cossette \& Misra, 2011; Duim et al., 2016; Manner et al., 2005; Zhou et al., 2008). We observe a re-activation of these genes after hypoxia exposure in a fraction of cells at the transcriptional level (cluster III, Figure 3A), as well as at the protein level (Figure 1I-J). Cluster I encompass a compartment of PO epicardial cells expressing the epicardial specific genes together with Kdr, Flt1, Pdgfb, Nos3, Cdh5 and Acta2. Co-expression in the same cell of epicardial, endothelial and Acta2 is compatible with an epicardial commitment to the endothelial lineage. Cluster II contains the majority of adult normoxic and hypoxic Gp38+ epicardial cells expressing stromal associated genes (Col3a1, Tmsb4x, Col1a1, Tcf21 and Tbx20), confirming their lineage relationship as shown by others(Cai et al., 2008; Dettman et al., 1998; Gittenberger-de Groot et al., 1998; Wessels \& Pérez-Pomares, 2004; Zhou et al., 2008). Cluster III and IV show high levels of epicardial specific genes (Wt1, Gpm6a, Bnc1 and $T b \times 18)$ indicative of the most immature epicardial profile. Cluster III differs from cluster IV due to the presence of hypoxia-primed epicardial cells and the additional expression of Cldn5. This cluster also diverges from cluster II, where the majority of the hypoxia-primed epicardial cells are, due to the reduction of the fibrotic genes (Tcf21, tbx2o, Tgfb1 and 
Col1a1, Figure 3A). This result reveals the acquisition of endothelial lineage transcript in the adult epicardial cells only following hypoxia exposure. The projection of the transcriptional data as UMAP1 vs. UMAP2 (Uniform Manifold Approximation and Projection, Figure 3B) show similarly to the heatmap clustering (Figure 3A), with 4 clusters of epicardial cells. The UMAP analysis highlights the similarities between cluster I (P0 epicardial cells) and cluster III (P0 and hypoxia-primed epicardial cells) with the differential expression of genes associated to the endothelial lineage (Figure 3B).

Based on single cell data, gene expression profiles corresponding to the major epicardial derived lineages, i.e. epicardial, stromal, endothelial and smooth muscle cells were analyzed (Figure $3 \mathrm{C}$ ). While the developing epicardium shows a mixed profile with cells expressing genes characteristic of all lineages (epicardial, stromal, endothelial and smooth muscle cells), the adult epicardial layer only expresses epicardium and stromal cell transcripts. In contrast, hypoxia-primed adult epicardium up-regulates the expression of endothelial and smooth muscle-associated genes in a subset of cells comparable to the developing epicardium profile (Figure 3C).

While not definitive, the determination of lineage trajectories can be proposed based upon multiplex single-cell experimental tools and diffusion maps (or pseudotemporal ordering) as shown by others(Haghverdi et al, 2016). We therefore generated diffusion maps for the 3 populations examined here. Similar to our observations with unsupervised clustering and tSNE analyses (Figure IV and V-B in the Supplement), we found that Gp38+ epicardial cells were more dispersed, whereas PDGFRa ${ }^{+}$stromal and $\mathrm{CD} 31^{+}$endothelial cells were found closer together (Figure 3D). The resulting trajectory initiates with the most immature phenotype $\left(\mathrm{Gp} 38^{+}\right.$cells, root, labeled 1) and splits into two distinct cell fates, the stromal cell (labeled 3) and endothelial cell (labeled 5). Developing epicardial cells (E17.5) are positioned at the root of the diffusion map (Figure 3D, labeled 1), followed by P0 epicardial cells (Figure 3D, labeled 2) and a split node into two branches: one of PDGFRa ${ }^{+}$cells (Figure 
3D, labeled 3); and another of $\mathrm{CD} 31^{+}$endothelial cells (Figure 3D, labeled 5). We noted a

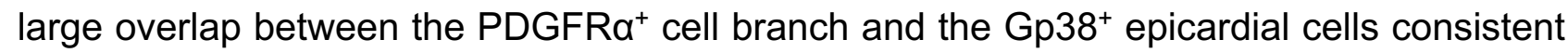
with a cell fate lineage relationship. Endothelial cell branch shows less overlap and is more clearly segregated from Gp38+ cells. However, we noted a fraction of hypoxia-primed adult

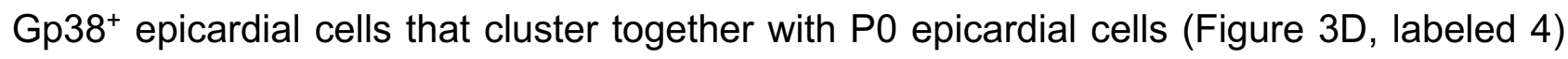
alongside the pathway of the endothelial cells fate. This result indicates that epicardial cells are distinct from the endothelial compartment. Overall, Gp38 ${ }^{+}$epicardial cells display a heterogeneous transcriptional profile for the genes analyzed consistent with the proposal that this compartment consists of progenitor cells that can give rise to multiple lineages. As expected, E17.5 and P0 derived epicardial cells have the most immature transcriptomes. A significant fraction of epicardial cells, irrespective of the stage or conditions from which they were isolated largely overlap with the PDGFRa ${ }^{+}$population which is in agreement with previous demonstrations of a lineage relationship between the epicardium and stromal/fibroblast cells(Acharya et al., 2012; Ali et al, 2014; Cai et al., 2008; Dettman et al., 1998; Gittenberger-de Groot et al., 1998; Grieskamp et al, 2011; Katz et al, 2012; Mikawa \& Gourdie, 1996; Perez-Pomares et al., 1997; Wessels et al., 2012; Zhou et al, 2011; Zhou et al, 2012a; Zhou et al., 2008). In addition, we observed that a distinct subset of P0 and hypoxia-primed epicardial cells cluster with the endothelial population, highlighting a potential contribution to the endothelium. These data suggest that the adult epicardium is activated to give rise to a population of cells with an endothelial cell fate potential in response to hypoxia, which has been proposed by others to occur during cardiac development(Limana et al, 2007; Wessels et al., 2012) as well as in non-mammalian vertebrates throughout life(Manner, 1993; Merki et al., 2005; Olivey et al., 2004; Poss et al., 2002).

\section{The epicardial in vitro stem cell potential is dependent upon hypoxia}


The cell fate potential of the epicardium can only be defined using reliable lineage markers which are presently unavailable. This limitation is further compounded by the currently available in vitro assays to study epicardial cells biology that are based on tissue explants and migratory potential of epicardial-derived cells (Bax et al., 2019; Cao \& Poss, 2016; Kim et al., 2012; Ramesh et al., 2016; Smart et al., 2007; Tran et al., 2016). Tissue explant assays do not allow for the determination of the main stem cell properties (i.e. self-renewal, clonogenicity and multipotency) and bias the study to cells able to migrate out of the explant. Our data reveals that epicardial cells are activated in response to hypoxia, raising the possibility that these cells require a hypoxic environment. Using our sorting strategy (Figure IIA in the Supplement), we prospectively isolated and freshly cultured $\mathrm{Gp} 38^{+} \mathrm{PW} 1^{+}$epicardial cells from fetal (E17.5), newborn (P0), and adult hearts both in normoxic $\left(21 \% \mathrm{O}_{2}\right)$ and in hypoxic $\left(1 \% \mathrm{O}_{2}\right)$ conditions (Figure $\left.4 \mathrm{~A}\right)$. We found that $\mathrm{Gp} 38^{+} \mathrm{PW} 1^{+}$epicardial cell growth was completely dependent upon hypoxic conditions regardless of their developmental state, whereas these cells did not expand in normoxic conditions and only few cells were present following several days in culture (Figure 4A-B). We noted that adult-derived epicardial cells displayed a significant decrease in the ability to grow in culture (Figure 4B). Because the ability of adult epicardial cells to grow in culture is decreased and the frequency of epicardial cells recovered from an adult heart is substantial smaller, we characterized the in vitro epicardial colonies potential using the developing epicardial Gp38+ cells (E17.5 and P0).

Low-density plating assays showed that $\mathrm{Gp} 38^{+} \mathrm{PW} 1^{+}$epicardial cells form colonies with an epithelial-like honeycomb morphology (Figure 4B-C). The developing (E17.5/P0) colonies displayed complete overlap of Gp38 and PW1 expression (Figure 4C), showing that hypoxia maintains their original profile (Figure 4A). Cell proliferation was assessed by $\mathrm{Ki} 67$ and $\mathrm{pH} 3$ expression and showed that $\sim 95 \%$ cells $\left(\mathrm{Gp} 38^{+} / \mathrm{Ki}^{+} 7^{+}\right)$were proliferative of which $5 \%$ were actively dividing (Gp38 $/ \mathrm{pH}^{+}$, Figure 4D and Figure VII in the Supplement). This profile was observed at D4 or D8 in culture (Figure VI in the Supplement), confirming that colony growth 
is due to proliferation of $\mathrm{Gp} 38^{+}$cells. Additionally, colonies shared a similar average size when derived from E17.5 and P0 (Figure 4D, right graph) revealing a similar growth potential in cells derived from early stages. We next characterized the colonies for each relevant epicardial lineage following 8 days in culture. We observed that PDGFRa was expressed in a subset of the colony (Figure 4E and Figure VII in the Supplement) and its expression is acquired by D4 (Figure VI in the Supplement). This result is consistent with previous observations that PDGFRa is expressed in epicardial-derived cells found in the subepicardial zone (Figure $2 \mathrm{C}-\mathrm{D})$. The $\mathrm{Gp} 38^{+} \mathrm{PW} 1^{+}$colonies also showed expression of the smooth the muscle cell markers aSMA and SM22 $\alpha$ (Figure 4F and Figure VII in the Supplement). The majority of cells within the colony expressed both proteins, however the co-expression of aSMA was associated with a smooth muscle-like cell morphology. We detected that colonies typically consisted of a centrally located core of cells that were round

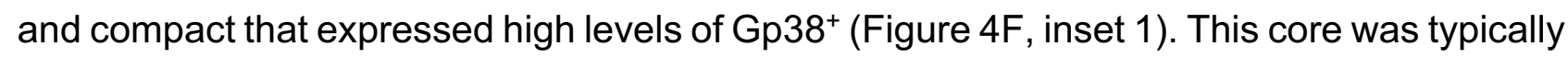
surrounded by an outer layer of differentiating $\alpha \mathrm{SMA}^{+}$cells with a lower nucleus/cytoplasm ratio and lower levels of Gp38 expression (Figure 4F, inset 2). Furthermore, we observed a widespread expression of Flk1, an early endothelial commitment marker (Figure 4G and Figure VII in the Supplement). While Flk1 expression confirms that the Gp $38^{+}$cells can give rise to the endothelial lineage, we did not observe CD31 expression, which likely reflects that our culture conditions, while suitable for cell expansion, are not optimized for full endothelial differentiation. We further confirmed the multipotential ability of the $\mathrm{Gp} 38^{+} \mathrm{Pw} 1^{+}$ cells to differentiate into smooth muscle, stromal and immature endothelial cells at the single cell level (Figure 4H). Taken together, we describe novel culture conditions that allow for the maintenance and expansion of $\mathrm{Gp} 38^{+} \mathrm{PW} 1^{+}$epicardial cells using hypoxic conditions and that these cells are multipotent progenitors for stromal cells, smooth muscle cells, and immature endothelial cells. 


\section{Physiological hypoxic priming induces the capacity to form CFU in adult epicardial} cells

$\mathrm{PW}^{+}{ }^{+} \mathrm{Gp} 38^{+}$epicardial cells constitute a minor overall cell population in the adult heart (Figure 2A) and the epicardium is relatively quiescent(Cossette \& Misra, 2011; Duim et al., 2016; Manner et al., 2005; Zhou et al., 2008) and but hypoxic(Kocabas et al., 2012). This raised the question whether in vivo hypoxia priming directly regulates epicardial progenitors. We compared the potential of $\mathrm{PW} 1^{+} \mathrm{Gp} 38^{+}$epicardial cells derived from E17.5, P0, adult normoxia or adult hypoxia-primed mice. Limiting dilution analysis showed that P0 and E17.5 gave rise to epicardial colonies at similar frequency (1/25 and $1 / 40$, respectively). Nevertheless, P0-derived $\mathrm{PW} 1^{+} \mathrm{Gp} 38^{+}$epicardial cells showed a higher capacity to form colonies (CFUs) as compared to cells derived from E17.5 (Figure 5A), which may reflect that the epicardium is most active during early postnatal growth when the bulk of coronary vasculature is formed/matured(Tian et al, 2014). Moreover, adult epicardial cells from normoxic mice showed an 8-fold and 13-fold lower CFU capacity (1/324) as compared to fetal and newborn derived epicardial cells, respectively (Figure 5A). We therefore tested the capacity of $\mathrm{PW} 1^{+} \mathrm{Gp} 38^{+}$epicardial cells derived from adult hearts following exposure to physiological hypoxia to test whether the level of oxygen accounted for CFU capacity. We found that the hypoxic 'priming' in vivo prior to culturing freshly isolated epicardial cells induced a 3-fold increase in the colony formation in vitro (Figure 5A-B). Furthermore, we found that the colonies derived from adult hypoxia-primed epicardial cells displayed a higher frequency of dividing cells $\left(\mathrm{pH}^{+}\right)$as well as of PDGFRa ${ }^{+}$cells similar to the behavior of colonies from newborn (P0) mice (Figure 5C-F), when the $\mathrm{PW} 1^{+} \mathrm{Gp} 38^{+}$epicardial cells were more active. In conclusion, these observations demonstrate that hypoxia provides a critical stimulus for epicardial cell growth, expansion and differentiation and that the low oxygen levels exposure in vivo play a critical role in promoting these activities. 


\section{Discussion}

The epicardium is a mesothelial layer that surrounds the heart of all vertebrates and gives rise to multiple cell lineages during heart development and regeneration. There is considerable research effort aimed at identifying factors that activate the adult epicardium in order to promote a beneficial recovery following cardiac injury(Cao \& Poss, 2018; Dube et al, 2017; Liu et al, 2014; Smart et al., 2011; van Wijk et al, 2012; Zangi et al, 2013; Zangi et al, 2017; Zhou et al., 2011; Zhou et al, 2012b). The embryonic and fetal hearts are physiologically hypoxic due to an underdeveloped cardiac vascular system and placenta restriction(Guimaraes-Camboa et al., 2015; Nanka et al., 2006; Olivetti et al., 1980; Patterson \& Zhang, 2010; Sayed et al, 2018; Tian et al., 2013; Tian et al., 2015; Tomanek, 1996; Wikenheiser et al., 2006), whereas the hypoxic state is only maintained in the adult mammalian epicardium, as shown in this study and by others(Kocabas et al., 2012). The epicardium has been shown to drive heart morphogenesis and serve as a reservoir of progenitors of non-cardiomyocyte lineages throughout life and in response to injury in nonmammalian vertebrates(Cai et al., 2008; Dettman et al., 1998; Gittenberger-de Groot et al., 1998; Mikawa \& Gourdie, 1996; Perez-Pomares et al., 1997; Wessels et al., 2012; Zhou et al., 2008). The progenitor capacity of the adult mammalian epicardial cells is less explored, but is considered to be less robust. Additionally, whereas the epicardium is a source of coronary endothelial cells in non-mammalian vertebrates, it is not clear if this property is maintained in mammals.

We demonstrated previously that PW1 is broadly expressed during embryonic development and maintained in multiple adult progenitor niches(Besson et al., 2011; Kuroiwa et al., 1996; Mitchell et al., 2010). We find a similar pattern of expression occurs in the heart with an initial widespread expression until early postnatal life and then restricted to the epicardium in the adult (Figure 6). 
Although, definitive models for cell fate tracing are needed to clearly address whether hypoxia induces an endothelial cell fate in $\mathrm{Gp}_{38}{ }^{+} \mathrm{PW} 1^{+}$epicardial cells and our single cell transcriptional data provides a static picture of cells at the time of isolation, it nonetheless provides an unbiased approach that strongly supports a model in which the multipotent epicardium contributes to cells with both stromal and endothelial lineage profiles. Hypoxia has been shown to decrease fibrotic scarring coupled with functional recovery of the heart following ischemia(Nakada et al., 2017) and we demonstrated previously that PW1 stromal cells contribute to fibrosis following myocardial infarction(Yaniz-Galende et al., 2017). Here, our single cell transcriptome analysis shows that epicardial cells are a heterogenous population. Gp38+PW1+ epicardial cells show a strong lineage relationship between epicardial cells and PDGFRa ${ }^{+}$cells (subepicardial and stromal cells) and, at less extent, but clearly more robust after hypoxia exposure, between epicardium and endothelial cells. The presence of a distinct subset of epicardial cells with endothelial lineage fate after hypoxia exposure is analogous to the developing epicardium profile, indicating the potential of adult resident epicardial cells to activate an immature endothelial cell program. We reported previously that cardiac $\mathrm{PW} 1^{+}$stromal cells can be purified based upon the expression of $\alpha \mathrm{V}$ integrin and that pharmacological inhibition of $\alpha \mathrm{V}$-integrin results in a potent inhibition of fibrosis in response to ischemia coupled with a reduced infarct size(Bouvet et al., 2020). Whether hypoxia and $\alpha \mathrm{V}$-integrin action share a common signaling pathway endpoint will be of interest to pursue. These results provide a cellular basis by which physiological hypoxia promotes angiogenesis. The precise pathways acting in response to hypoxia likely involve well characterized cell stress pathways that are also regulated by $P w 1$, such as TNF $\alpha-N F \kappa B$ signaling in cell growth and survival(Relaix et al., 1998) and p53 signaling in apoptosis(Deng \& Wu, 2000; Relaix et al., 2000), as well as the glucose metabolism regulation(Correra et al., 2018). 
This study also provides a novel strategy to purify and culture Gp38+PW1+ epicardial cells that will prove invaluable to further dissect mechanisms underlying the role of epicardial cells during injury and repair. Perinatal-derived $\mathrm{PW} 1^{+} \mathrm{Gp} 38^{+}$epicardial cells show clonogenicity, self-renewal and multipotency properties at the single cell level and can differentiate into PDGFRa ${ }^{+}$cells (subepicardial and stromal cells), $\alpha S M A^{+} S M 22 \alpha^{+}$smooth muscle cells and Flk $1^{+}$immature endothelial cells. This cell fate potential is dependent upon oxygen levels. We further show that epicardial cells isolated from the adult heart markedly improved following in vivo hypoxic priming their ability to be maintained and expanded in vitro. Taken together, this study demonstrates that resident $\mathrm{Gp} 38^{+} \mathrm{PW} 1^{+}$epicardial cells retain progenitor competence in the adult mammalian heart and that hypoxia is critical to promote progenitor expansion and multi-lineage differentiation, including the activation of endothelial cell fates. These finding serve as a basis to design therapeutic approaches to promote heart revascularization and provide an invaluable in vitro model for further studies.

\section{Methods}

A detailed methods section is provided as Online Supplement Material.

\section{Mice}

C57BL/6J mice from Janvier and PW1 IRESnLacZ $\left(P W 1^{n l a c Z}\right)$ transgenic reporter mice(Besson et al., 2011) were used. All animal procedures were approved by our institutional research committee (CEEA34 and French ministry of research) and followed the animal care guideline in Directive 2010/63/EU European Parliament.

\section{In vivo hypoxia}


A cage connected to nitrogen and oxygen gas (ProOxP360, Biospherix) was used for the in vivo hypoxia with controlled atmosphere by silica gel (Carlo Erba) and soda lime (Intersurgical). Mice were exposed to hypoxia $\left(10 \% \mathrm{O}_{2}\right)$ during 2 weeks.

\section{Cardiac cell suspension}

Heart fragments were incubated at $37^{\circ} \mathrm{C}$ with enzymatic solution (Collagenase II and DNase I) for serial rounds of digestion.

\section{Flow cytometry and cell sorting}

Cell suspensions were stained with a panel of surface antibodies, $C_{12}$ FDG to detect $ß-$ galactosidase activity and viability dye before flow cytometry analysis. The list of antibodies for flow cytometry is provided in Supplemental Material.

\section{Primary cell culture and cell immunofluorescence staining}

Sorted epicardial cells $\left(\mathrm{Gp} 38^{+} \mathrm{PW} 1^{+}\right)$were plated in amplification medium under normoxia $\left(21 \% \mathrm{O}_{2}\right)$ or acute hypoxia $\left(1 \% \mathrm{O}_{2}\right)$ for 8 days. Cells were fixed, permeabilized and blocked. Primary antibodies were incubated followed by the adequate secondary antibodies and counterstained with DAPI. The list of antibodies for cell culture is provided in Supplemental Material.

\section{Histological processing and tissue immunofluorescence staining}

Hearts were frozen, embedded in OCT and cut in four distinct coronal regions. Sections were fixed, permeabilized and blocked. Primary antibodies were incubated followed by the adequate secondary antibodies and counterstained with DAPI. The list of antibodies for histology is provided in Supplemental Material. 


\section{X-gal staining}

ß-galactosidase activity (LacZ) was detected in heart cryosections as described previously(Relaix et al, 2004; Sanes et al, 1986; Zakany et al, 1988).

\section{Pimonidazole injection and detection}

Pimonidazole was injected intraperitonealy in adult mice (90 minutes incubation) and injected subcutaneously in newborn mice (3 hours incubation) before heart collection. Hearts were frozen and pimonidazole was detected with MAb1 (Hydroxyprobe), according to the manufacturer's instructions.

\section{Multiplex qPCR (bulk and single cell)}

Cells were sorted directly into RT-STA reaction mix (CellsDirect One-Step qRTPCR Kit) and 0.2x specific TaqMan Assay mix. Taqman assays are listed in Supplemental Material. Multiplex qPCR was preformed using the microfluidics Biomark HD system (Fluidigm) as previously described(Chea et al, 2016) for the same TaqMan Assay panel in Supplemental Material.

\section{Bioinformatic analysis}

Gene expression raw data (Biomark, Fluidigm) of both bulk and single cell were normalized with Gapdh housekeeping gene, and 'heatmap', 'Rphenograph' and 'diffusion map' were created using $\mathrm{R}$ packages(Levine et al, 2015).

\section{Quantifications and statistical analyses}

Histological images were analyzed with Icy software(de Chaumont et al, 2012). Graphs and statistics were performed with Prism software (GraphPad). The line in the box plots represents the median value. For the statistical comparison, two groups were tested by 
Mann-Whitney $U$ test and for more than two groups one-way analysis of variance (ANOVA) was used. A value of $p<0.05$ was considered significant. Biological replicates represent independent experiments.

\section{Acknowledgements:}

We thank the members of D.S. and J.S.H. laboratories for fruitful discussions. We thank Ana Cumano (Institut Pasteur) and Zeina al Sayed (PARCC) for careful reading and discussion. We are grateful to the flow cytometry platforms (Catherine Blanc and Bénédicte Hoareau-Coudert from CyPS Pierre et Marie Curie University and to Camille Knosp from PARCC), to the animal facility platform for their help handling mouse lines (to the Pierre et Marie Curie University animal facility and to ERI at PARCC), to Sophie Nadaud for the technical help with the establishment of the in vivo hypoxia environment, to Priya Kantane for technical support, to the assistance in the Biomark (Valentina Libri and Valérie Feffer from Cytometry and Biomarkers UTechS, Institut Pasteur).

\section{Author contributions:}

A.S. and M.V. conceived and performed experiments, performed formal analysis, and wrote the manuscript; S.T. performed experiments and analysis; F.S.S. provided analysis assistance and discussion, G.M., D.S., J.S.H. provided feedback and reviewed the manuscript; D.S. and J.S.H. secured funding.

\section{Funding:}

This work was supported by a grant from the Fondation Leducq (13CVD01), Fédération Française de Cardiologie, Era-CVD (ANR-16-ECVD-0011-03), ANR PACIFIC (ANR-18-CE14-0032-02), ANR REVIVE (F.S.S. and M.V. Laboratoire d'Excellence; ANR-10-LABX-73), Le Fonds Marion Elizabeth 
BRANCHER (A.S.) and GENMED Laboratory of Excellence on Medical Genomics (ANR-10-LABX0013).

Sources of funding: Outside the submitted work, JSH is supported by AP-HP, INSERM, the French National Research Agency (NADHeart ANR-17-CE17-0015-02, PACIFIC ANR-18-CE14-0032-01, CORRECT_LMNA ANR-19-CE17-0013-02), the ERA-Net-CVD (ANR-16-ECVD-0011-03, Clarify project), Fédération Française de Cardiologie, the Fondation pour la Recherche Médicale (EQU201903007852), and by a grant from the Leducq Foundation (18CVD05), and is coordinating a French PIA Project (2018-PSPC-07, PACIFIC-preserved, BPIFrance) and a University Research Federation against heart failure (FHU2019, PREVENT_Heart Failure).

Disclosures: JSH reports research grants from Bioserenity, Sanofi, Servier and Novo Nordisk; speaker, advisory board or consultancy fees from Amgen, Astra Zeneca, Bayer, Bioserenity, Bristol-Myers Squibb, Novartis, Novo-Nordisk, all unrelated to the present work. Other authors declare no competing financial interests.

\section{Supplemental Materials}

Expanded Methods

Supplemental Tables I

Supplemental

Figures I - VII 


\section{References}

Acharya A, Baek ST, Huang G, Eskiocak B, Goetsch S, Sung CY, Banfi S, Sauer MF, Olsen GS, Duffield JS et al (2012) The bHLH transcription factor Tcf21 is required for lineagespecific EMT of cardiac fibroblast progenitors. Development 139: 2139-2149

Ali SR, Ranjbarvaziri S, Talkhabi M, Zhao P, Subat A, Hojjat A, Kamran P, Muller AM, Volz KS, Tang Z et al (2014) Developmental heterogeneity of cardiac fibroblasts does not predict pathological proliferation and activation. Circ Res 115: 625-635

Bax NAM, Duim SN, Kruithof BPT, Smits AM, Bouten CVC, Goumans MJ (2019) In vivo and in vitro Approaches Reveal Novel Insight Into the Ability of Epicardium-Derived Cells to Create Their Own Extracellular Environment. Front Cardiovasc Med 6: 81

Besson V, Smeriglio P, Wegener A, Relaix F, Nait Oumesmar B, Sassoon DA, Marazzi G (2011) PW1 gene/paternally expressed gene 3 (PW1/Peg3) identifies multiple adult stem and progenitor cell populations. Proc Natl Acad Sci U S A 108: 11470-11475

Bouvet M, Claude O, Roux M, Skelly D, Masurkar N, Mougenot N, Nadaud S, Blanc C, Delacroix C, Chardonnet S et al (2020) Anti-integrin alphav therapy improves cardiac fibrosis after myocardial infarction by blunting cardiac PW1(+) stromal cells. Sci Rep 10: 11404 Cai CL, Martin JC, Sun Y, Cui L, Wang L, Ouyang K, Yang L, Bu L, Liang X, Zhang X et al (2008) A myocardial lineage derives from Tbx18 epicardial cells. Nature 454: 104-108

Cao J, Poss KD (2016) Explant culture of adult zebrafish hearts for epicardial regeneration studies. Nat Protoc 11: 872-881

Cao J, Poss KD (2018) The epicardium as a hub for heart regeneration. Nat Rev Cardiol 15: 631-647

Chea S, Schmutz S, Berthault C, Perchet T, Petit M, Burlen-Defranoux O, Goldrath AW, Rodewald HR, Cumano A, Golub R (2016) Single-Cell Gene Expression Analyses Reveal Heterogeneous Responsiveness of Fetal Innate Lymphoid Progenitors to Notch Signaling. Cell Rep 14: 1500-1516

Christoffels VM, Grieskamp T, Norden J, Mommersteeg MT, Rudat C, Kispert A (2009) Tbx18 and the fate of epicardial progenitors. Nature 458: E8-9; discussion E9-10

Correra RM, Ollitrault D, Valente M, Mazzola A, Adalsteinsson BT, Ferguson-Smith AC, Marazzi G, Sassoon DA (2018) The imprinted gene Pw1/Peg3 regulates skeletal muscle growth, satellite cell metabolic state, and self-renewal. Sci Rep 8: 14649

Cossette S, Misra R (2011) The identification of different endothelial cell populations within the mouse proepicardium. Dev Dyn 240: 2344-2353

de Chaumont F, Dallongeville S, Chenouard N, Herve N, Pop S, Provoost T, Meas-Yedid V, Pankajakshan P, Lecomte T, Le Montagner $Y$ et al (2012) Icy: an open bioimage informatics platform for extended reproducible research. Nat Methods 9: 690-696

Deng Y, Wu X (2000) Peg3/Pw1 promotes p53-mediated apoptosis by inducing Bax translocation from cytosol to mitochondria. Proc Natl Acad Sci U S A 97: 12050-12055

Dettman RW, Denetclaw W, Jr., Ordahl CP, Bristow J (1998) Common epicardial origin of coronary vascular smooth muscle, perivascular fibroblasts, and intermyocardial fibroblasts in the avian heart. Dev Biol 193: 169-181

Dube KN, Thomas TM, Munshaw S, Rohling M, Riley PR, Smart N (2017) Recapitulation of developmental mechanisms to revascularize the ischemic heart. JCI Insight 2

Duim SN, Kurakula K, Goumans MJ, Kruithof BP (2015) Cardiac endothelial cells express Wilms' tumor-1: Wt1 expression in the developing, adult and infarcted heart. $\mathrm{J}$ Mol Cell Cardiol 81: 127-135

Duim SN, Smits AM, Kruithof BP, Goumans MJ (2016) The roadmap of WT1 protein expression in the human fetal heart. $J$ Mol Cell Cardiol 90: 139-145 
Eschenhagen T, Bolli R, Braun T, Field LJ, Fleischmann BK, Frisen J, Giacca M, Hare JM, Houser S, Lee RT et al (2017) Cardiomyocyte Regeneration: A Consensus Statement. Circulation 136: 680-686

Feng W, Marquez RT, Lu Z, Liu J, Lu KH, Issa JP, Fishman DM, Yu Y, Bast RC, Jr. (2008) Imprinted tumor suppressor genes $\mathrm{ARHI}$ and PEG3 are the most frequently down-regulated in human ovarian cancers by loss of heterozygosity and promoter methylation. Cancer 112: 1489-1502

Giaccia AJ, Simon MC, Johnson R (2004) The biology of hypoxia: the role of oxygen sensing in development, normal function, and disease. Genes Dev 18: 2183-2194

Gittenberger-de Groot AC, Vrancken Peeters MP, Mentink MM, Gourdie RG, Poelmann RE (1998) Epicardium-derived cells contribute a novel population to the myocardial wall and the atrioventricular cushions. Circ Res 82: 1043-1052

Grieskamp T, Rudat C, Ludtke TH, Norden J, Kispert A (2011) Notch signaling regulates smooth muscle differentiation of epicardium-derived cells. Circ Res 108: 813-823

Guimaraes-Camboa N, Stowe J, Aneas I, Sakabe N, Cattaneo P, Henderson L, Kilberg MS, Johnson RS, Chen J, McCulloch AD et al (2015) HIF1alpha Represses Cell Stress Pathways to Allow Proliferation of Hypoxic Fetal Cardiomyocytes. Dev Cell 33: 507-521

Haghverdi L, Buttner M, Wolf FA, Buettner F, Theis FJ (2016) Diffusion pseudotime robustly reconstructs lineage branching. Nat Methods 13: 845-848

Haubner BJ, Adamowicz-Brice M, Khadayate S, Tiefenthaler V, Metzler B, Aitman T, Penninger JM (2012) Complete cardiac regeneration in a mouse model of myocardial infarction. Aging (Albany NY) 4: 966-977

Hesse J, Groterath W, Owenier C, Steinhausen J, Ding Z, Steckel B, Czekelius C, Alter C, Marzoq A, Schrader J (2021a) Normoxic induction of HIF-1alpha by adenosine-A2B R signaling in epicardial stromal cells formed after myocardial infarction. FASEB J 35: e21517 Hesse J, Owenier C, Lautwein T, Zalfen R, Weber JF, Ding Z, Alter C, Lang A, Grandoch M, Gerdes N et al (2021b) Single-cell transcriptomics defines heterogeneity of epicardial cells and fibroblasts within the infarcted murine heart. Elife 10

Hou TZ, Bystrom J, Sherlock JP, Qureshi O, Parnell SM, Anderson G, Gilroy DW, Buckley CD (2010) A distinct subset of podoplanin (gp38) expressing F4/80+ macrophages mediate phagocytosis and are induced following zymosan peritonitis. FEBS Lett 584: 3955-3961

Huang X, Trinh T, Aljoufi A, Broxmeyer HE (2018) Hypoxia Signaling Pathway in Stem Cell Regulation: Good and Evil. Curr Stem Cell Rep 4: 149-157

Jing X, Gao Y, Xiao S, Qin Q, Wei X, Yan Y, Wu L, Deng S, Du J, Liu Y et al (2016) Hypoxia induced the differentiation of Tbx18-positive epicardial cells to CoSMCs. Sci Rep 6: 30468 Katz TC, Singh MK, Degenhardt K, Rivera-Feliciano J, Johnson RL, Epstein JA, Tabin CJ (2012) Distinct compartments of the proepicardial organ give rise to coronary vascular endothelial cells. Dev Cell 22: 639-650

Kim J, Rubin N, Huang Y, Tuan TL, Lien CL (2012) In vitro culture of epicardial cells from adult zebrafish heart on a fibrin matrix. Nat Protoc 7: 247-255

Kocabas F, Mahmoud AI, Sosic D, Porrello ER, Chen R, Garcia JA, DeBerardinis RJ, Sadek HA (2012) The hypoxic epicardial and subepicardial microenvironment. J Cardiovasc TransI Res 5: 654-665

Kohda T, Asai A, Kuroiwa Y, Kobayashi S, Aisaka K, Nagashima G, Yoshida MC, Kondo Y, Kagiyama N, Kirino T et al (2001) Tumour suppressor activity of human imprinted gene PEG3 in a glioma cell line. Genes Cells 6: 237-247

Krohn KA, Link JM, Mason RP (2008) Molecular imaging of hypoxia. J Nucl Med 49 Suppl 2: $129 \mathrm{~S}-148 \mathrm{~S}$

Kuroiwa Y, Kaneko-Ishino T, Kagitani F, Kohda T, Li LL, Tada M, Suzuki R, Yokoyama M, Shiroishi T, Wakana S et al (1996) Peg3 imprinted gene on proximal chromosome 7 encodes for a zinc finger protein. Nat Genet 12: 186-190 
Levine JH, Simonds EF, Bendall SC, Davis KL, Amir el AD, Tadmor MD, Litvin O, Fienberg HG, Jager A, Zunder ER et al (2015) Data-Driven Phenotypic Dissection of AML Reveals Progenitor-like Cells that Correlate with Prognosis. Cell 162: 184-197

Limana F, Zacheo A, Mocini D, Mangoni A, Borsellino G, Diamantini A, De Mori R, Battistini L, Vigna E, Santini M et al (2007) Identification of myocardial and vascular precursor cells in human and mouse epicardium. Circ Res 101: 1255-1265

Liu Q, Huang X, Oh JH, Lin RZ, Duan S, Yu Y, Yang R, Qiu J, Melero-Martin JM, Pu WT et al (2014) Epicardium-to-fat transition in injured heart. Cell Res 24: 1367-1369

Mahtab EA, Wijffels MC, Van Den Akker NM, Hahurij ND, Lie-Venema H, Wisse LJ, Deruiter MC, Uhrin P, Zaujec J, Binder BR et al (2008) Cardiac malformations and myocardial abnormalities in podoplanin knockout mouse embryos: Correlation with abnormal epicardial development. Dev Dyn 237: 847-857

Manner J (1993) Experimental study on the formation of the epicardium in chick embryos. Anat Embryol (Berl) 187: 281-289

Manner J, Schlueter J, Brand T (2005) Experimental analyses of the function of the proepicardium using a new microsurgical procedure to induce loss-of-proepicardial-function in chick embryos. Dev Dyn 233: 1454-1463

Merki E, Zamora M, Raya A, Kawakami Y, Wang J, Zhang X, Burch J, Kubalak SW, Kaliman $\mathrm{P}$, Izpisua Belmonte JC et al (2005) Epicardial retinoid $\mathrm{X}$ receptor alpha is required for myocardial growth and coronary artery formation. Proc Natl Acad Sci U S A 102: 1845518460

Mikawa T, Gourdie RG (1996) Pericardial mesoderm generates a population of coronary smooth muscle cells migrating into the heart along with ingrowth of the epicardial organ. Dev Biol 174: 221-232

Mitchell KJ, Pannerec A, Cadot B, Parlakian A, Besson V, Gomes ER, Marazzi G, Sassoon DA (2010) Identification and characterization of a non-satellite cell muscle resident progenitor during postnatal development. Nat Cell Biol 12: 257-266

Nakada Y, Canseco DC, Thet S, Abdisalaam S, Asaithamby A, Santos CX, Shah AM, Zhang H, Faber JE, Kinter MT et al (2017) Hypoxia induces heart regeneration in adult mice. Nature 541: 222-227

Nanka O, Valasek P, Dvorakova M, Grim M (2006) Experimental hypoxia and embryonic angiogenesis. Dev Dyn 235: 723-733

Nunn A, Linder K, Strauss HW (1995) Nitroimidazoles and imaging hypoxia. Eur J Nucl Med 22: $265-280$

Olivetti G, Anversa P, Loud AV (1980) Morphometric study of early postnatal development in the left and right ventricular myocardium of the rat. II. Tissue composition, capillary growth, and sarcoplasmic alterations. Circulation Research 46: 503

Olivey HE, Compton LA, Barnett JV (2004) Coronary vessel development: the epicardium delivers. Trends Cardiovasc Med 14: 247-251

Patterson AJ, Zhang L (2010) Hypoxia and fetal heart development. Curr Mol Med 10: 653666

Perez-Pomares JM, Carmona R, Gonzalez-Iriarte M, Atencia G, Wessels A, Munoz-Chapuli $R$ (2002) Origin of coronary endothelial cells from epicardial mesothelium in avian embryos. Int J Dev Biol 46: 1005-1013

Perez-Pomares JM, Macias D, Garcia-Garrido L, Munoz-Chapuli R (1997) Contribution of the primitive epicardium to the subepicardial mesenchyme in hamster and chick embryos. Dev Dyn 210: 96-105

Porrello ER, Mahmoud AI, Simpson E, Hill JA, Richardson JA, Olson EN, Sadek HA (2011) Transient regenerative potential of the neonatal mouse heart. Science 331: 1078-1080 Poss KD, Wilson LG, Keating MT (2002) Heart regeneration in zebrafish. Science 298: 2188-2190 
Ramesh S, Singh A, Cibi DM, Hausenloy DJ, Singh MK (2016) In Vitro Culture of Epicardial Cells From Mouse Embryonic Heart. $J$ Vis Exp

Red-Horse K, Ueno H, Weissman IL, Krasnow MA (2010) Coronary arteries form by developmental reprogramming of venous cells. Nature 464: 549-553

Relaix F, Rocancourt D, Mansouri A, Buckingham M (2004) Divergent functions of murine Pax3 and Pax7 in limb muscle development. Genes Dev 18: 1088-1105

Relaix F, Wei X, Li W, Pan J, Lin Y, Bowtell DD, Sassoon DA, Wu X (2000) Pw1/Peg3 is a potential cell death mediator and cooperates with Siah1a in p53-mediated apoptosis. Proc Natl Acad Sci U S A 97: 2105-2110

Relaix F, Wei XJ, Wu X, Sassoon DA (1998) Peg3/Pw1 is an imprinted gene involved in the TNF-NFkappaB signal transduction pathway. Nat Genet 18: 287-291

Rudat C, Kispert A (2012) Wt1 and epicardial fate mapping. Circ Res 111: 165-169

Sampaio-Pinto V, Rodrigues SC, Laundos TL, Silva ED, Vasques-Novoa F, Silva AC, Cerqueira RJ, Resende TP, Pianca N, Leite-Moreira A et al (2018) Neonatal Apex Resection Triggers Cardiomyocyte Proliferation, Neovascularization and Functional Recovery Despite Local Fibrosis. Stem Cell Reports 10: 860-874

Sanes JR, Rubenstein JL, Nicolas JF (1986) Use of a recombinant retrovirus to study postimplantation cell lineage in mouse embryos. EMBO J 5: 3133-3142

Sayed A, Valente M, Sassoon D (2018) Does cardiac development provide heart research with novel therapeutic approaches? F1000Research 7

Schwarzkopf M, Coletti D, Sassoon D, Marazzi G (2006) Muscle cachexia is regulated by a p53-PW1/Peg3-dependent pathway. Genes Dev 20: 3440-3452

Smart N, Bollini S, Dube KN, Vieira JM, Zhou B, Davidson S, Yellon D, Riegler J, Price AN, Lythgoe MF et al (2011) De novo cardiomyocytes from within the activated adult heart after injury. Nature

Smart N, Risebro CA, Melville AAD, Moses K, Schwartz RJ, Chien KR, Riley PR (2007) Thymosin [bgr]4 induces adult epicardial progenitor mobilization and neovascularization. Nature 445: 177-182

Soonpaa MH, Kim KK, Pajak L, Franklin M, Field LJ (1996) Cardiomyocyte DNA synthesis and binucleation during murine development. Am J Physiol 271: H2183-2189

Stellato M, Czepiel M, Distler O, Blyszczuk P, Kania G (2019) Identification and Isolation of Cardiac Fibroblasts From the Adult Mouse Heart Using Two-Color Flow Cytometry. Front Cardiovasc Med 6: 105

Sugishita Y, Leifer DW, Agani F, Watanabe M, Fisher SA (2004) Hypoxia-responsive signaling regulates the apoptosis-dependent remodeling of the embryonic avian cardiac outflow tract. Dev Biol 273: 285-296

Tao J, Barnett JV, Watanabe M, Ramirez-Bergeron D (2018) Hypoxia Supports Epicardial Cell Differentiation in Vascular Smooth Muscle Cells through the Activation of the TGFbeta Pathway. J Cardiovasc Dev Dis 5

Tian X, Hu T, Zhang H, He L, Huang X, Liu Q, Yu W, He L, Yang Z, Yan Y et al (2014) Vessel formation. De novo formation of a distinct coronary vascular population in neonatal heart. Science 345: 90-94

Tian X, Hu T, Zhang H, He L, Huang X, Liu Q, Yu W, He L, Yang Z, Zhang Z et al (2013) Subepicardial endothelial cells invade the embryonic ventricle wall to form coronary arteries. Cell Res 23: 1075-1090

Tian X, Pu WT, Zhou B (2015) Cellular origin and developmental program of coronary angiogenesis. Circ Res 116: 515-530

Tomanek RJ (1996) Formation of the coronary vasculature: a brief review. Cardiovasc Res 31 Spec No: E46-51

Tomanek RJ, Lund DD, Yue X (2003) Hypoxic induction of myocardial vascularization during development. Adv Exp Med Biol 543: 139-149 
Tran JR, Zheng X, Zheng Y (2016) Lamin-B1 contributes to the proper timing of epicardial cell migration and function during embryonic heart development. Mol Biol Cell 27: 39563963

Valente M, Resende TP, Nascimento DS, Burlen-Defranoux O, Soares-da-Silva F, Dupont B, Cumano A, Pinto-do OP (2019) Mouse HSA+ immature cardiomyocytes persist in the adult heart and expand after ischemic injury. PLoS Biol 17: e3000335

van Wijk B, Gunst QD, Moorman AF, van den Hoff MJ (2012) Cardiac regeneration from activated epicardium. PLoS One 7: e44692

Weninger W, Partanen TA, Breiteneder-Geleff S, Mayer C, Kowalski H, Mildner M, Pammer J, Sturzl M, Kerjaschki D, Alitalo K et al (1999) Expression of vascular endothelial growth factor receptor-3 and podoplanin suggests a lymphatic endothelial cell origin of Kaposi's sarcoma tumor cells. Lab Invest 79: 243-251

Wessels A, Pérez-Pomares JM (2004) The epicardium and epicardially derived cells (EPDCs) as cardiac stem cells. The Anatomical Record Part A: Discoveries in Molecular, Cellular, and Evolutionary Biology 276A: 43-57

Wessels A, van den Hoff MJ, Adamo RF, Phelps AL, Lockhart MM, Sauls K, Briggs LE, Norris RA, van Wijk B, Perez-Pomares JM et al (2012) Epicardially derived fibroblasts preferentially contribute to the parietal leaflets of the atrioventricular valves in the murine heart. Dev Biol 366: 111-124

Wikenheiser J, Doughman YQ, Fisher SA, Watanabe M (2006) Differential levels of tissue hypoxia in the developing chicken heart. Dev Dyn 235: 115-123

Winter EM, Gittenberger-de Groot AC (2007) Epicardium-derived cells in cardiogenesis and cardiac regeneration. Cell Mol Life Sci 64: 692-703

Yaniz-Galende E, Roux M, Nadaud S, Mougenot N, Bouvet M, Claude O, Lebreton G, Blanc C, Pinet F, Atassi F et al (2017) Fibrogenic Potential of PW1/Peg3 Expressing Cardiac Stem Cells. J Am Coll Cardiol 70: 728-741

Zakany J, Tuggle CK, Patel MD, Nguyen-Huu MC (1988) Spatial regulation of homeobox gene fusions in the embryonic central nervous system of transgenic mice. Neuron 1: 679691

Zangi L, Lui KO, von Gise A, Ma Q, Ebina W, Ptaszek LM, Spater D, Xu H, Tabebordbar M, Gorbatov R et al (2013) Modified mRNA directs the fate of heart progenitor cells and induces vascular regeneration after myocardial infarction. Nat Biotechnol 31: 898-907

Zangi L, Oliveira MS, Ye LY, Ma Q, Sultana N, Hadas Y, Chepurko E, Spater D, Zhou B, Chew WL et al (2017) Insulin-Like Growth Factor 1 Receptor-Dependent Pathway Drives Epicardial Adipose Tissue Formation After Myocardial Injury. Circulation 135: 59-72

Zhou B, Honor LB, He H, Ma Q, Oh JH, Butterfield C, Lin RZ, Melero-Martin JM, Dolmatova E, Duffy HS et al (2011) Adult mouse epicardium modulates myocardial injury by secreting paracrine factors. J Clin Invest 121: 1894-1904

Zhou B, Honor LB, Ma Q, Oh JH, Lin RZ, Melero-Martin JM, von Gise A, Zhou P, Hu T, He $\mathrm{L}$ et al (2012a) Thymosin beta 4 treatment after myocardial infarction does not reprogram epicardial cells into cardiomyocytes. J Mol Cell Cardiol 52: 43-47

Zhou B, Ma Q, Rajagopal S, Wu SM, Domian I, Rivera-Feliciano J, Jiang D, von Gise A, Ikeda S, Chien KR et al (2008) Epicardial progenitors contribute to the cardiomyocyte lineage in the developing heart. Nature 454: 109-113

Zhou H, Bian Z-Y, Zong J, Deng W, Yan L, Shen D-F, Guo H, Dai J, Yuan Y, Zhang R et al (2012b) Stem Cell Antigen 1 Protects Against Cardiac Hypertrophy and Fibrosis After Pressure Overload. Hypertension 60: 802-809 


\section{Figure legends}

Figure 1. Two-weeks hypoxia exposure induces the reactivation of an epicardiumspecific developmental growth program including proliferation and WT1 expression

A. Schema of chronic hypoxia induction $\left(10 \% \mathrm{O}_{2}\right)$ in the adult mice. B. Hypoxic regions stain with Pimonidazole in P0, normoxic and hypoxic adult ventricles. Scale bar: $20 \mu \mathrm{m}$ (top panels), scale bar: 10 $\mu \mathrm{m}$ (bottom panels). C. Pimonidazole expression increases under hypoxia exposure (n=3). D. Epicardial and subepicardial layer determined by PDGFRa and Laminin staining in P0, normoxic and hypoxic adult ventricles. Scale bar: $10 \mu \mathrm{m}$. E. Increase of epicardial and subepicardial thickness in hypoxic mice $(n=3,20$ images per heart, 5 measures per image and per layer). F. Higher number of nuclei in hypoxic mice ( $n=3,20$ images per heart). G. Proliferative PDGFRa ${ }^{+}$and $\mathrm{CD}_{3} 1^{+}$cells determined with $\mathrm{pH} 3$, in normoxic and hypoxic adult ventricles. Scale bar: $20 \mu \mathrm{m}$ (top panels), $10 \mu \mathrm{m}$ (bottom panels). $H$. Overall increase of proliferative cell in hypoxic mice $(n=3,20$ images per heart and per region). I. Immunostaining of WT1, a marker of epicardial activation. Scale bar: $20 \mu \mathrm{m}$ (top panels), 10 $\mu \mathrm{m}$ (bottom panel). J. Increase of WT1 expression particularly in the epicardial, subepicardial and endothelial cells in hypoxic mice $(n=3,20$ images per heart and per region).

All nuclei were counterstained with DAPI. Dashed line delineates the epicardial (Epic) layer. Values are normalized by the total number of nuclei per layer and per field and all values are represented in percentage. The line in the box plot represents the median. Statistical significance was determined either by Mann-Whitney test or by one-way ANOVA (KruskalWallis test) with uncorrected Dunn's test, for 2 groups or 3 groups comparison, respectively. ${ }^{* * * *} p<0.0001,{ }^{* * *} p<0.001,{ }^{* *} p<0.01$. P0: postnatal day 0, Ad: Adult, H: Hypoxia, Epic: Epicardium, SubEpic: Subepicardium, Neg: Negative Fraction.

Figure 2: Adult mice exposed to chronic hypoxia (10\%) upregulate PW1 expression 


\section{in the activated epicardium and subepicardium.}

A. Flow cytometry profiles and gating strategy of P0, Ad, and Ad-Hypoxia cardiac cell suspensions stained with CD31, PDGFRa and Gp38. B. Pw1-FDG ${ }^{+}$cells increase particularly in the endothelial and epicardial cell compartment after hypoxia induction in adult mice (n=3). C. Co-staining of PW1, Gp38 and PDGFRa in hypoxic mice (left panel). Scale bar: $20 \mu \mathrm{m}$ (upper), 10 $\mu \mathrm{m}$ (bottom). D. Co-staining of PW1, CD31 and PDGFRa in hypoxic adult ventricles. Scale bar: 10 $\mu \mathrm{m}$. E. Increase of PW1 expression in the epicardium (Gp38+) and subepicardium (PDGFRa ${ }^{+}$and negative cell fraction) in hypoxic adult ventricle ( $\mathrm{n}=3,20$ images per heart and per region). F. Co-expression of PW1 with pimonidazole in the epicardium and subepicardium in P0 and adult ventricles. Scale bar: $20 \mu \mathrm{m}$ (left panels), 10 $\mu \mathrm{m}$ (right panels). G. Co-staining of Pw1- $\beta$-gal with WT1 and PDGFRa in hypoxic adult mice. Scale bar: $10 \mu \mathrm{m}$. All nuclei were counterstained with DAPI. Values are normalized by the total number of nuclei per layer and per fields and all values are represented in percentage. Dashed line delineates the epicardial (Epic) layer. The line in the box plot represents the median. Statistical significance was determined by one-way ANOVA (Kruskal-Wallis test) with uncorrected Dunn's test. ${ }^{* * *} p<0.0001,{ }^{* * *} p<0.001,{ }^{* *} p<0.01,{ }^{*} p<0.05$. Epic: Epicardium, SubEpic: SubEpicardium, Myo: Myocardium, P0: postnatal day 0, Ad: Adult, H: Hypoxia, Pw1-FDG: Pw1-associated 5-Dodecanoylaminofluorescein Di- $\beta$-DGalactopyranoside, PIMO: Pimonidazole.

Figure 3. Transcriptional profiling demonstrates the activation of the epicardial developmental growth program in response to chronic hypoxia and a lineage overlap with PDGFRa ${ }^{+}$and $\mathrm{CD} 1^{+}$cells. A. Multiplex qPCR heat-map at single cell level reveals heterogeneity of the Gp38+ epicardial compartment from P0, Ad (adult) and H-Ad (hypoxic adult). Each column represents one cell with the corresponding color-code according cell type and physiological state. Hierarchical clustering reveals 4 major group of cells labeled I, 
II, III, IV with the differentially expressed genes listed below. A total of 168 cells were analyzed. Gene expression was normalized to Gapdh, and unsupervised hierarchical clustering was performed. B. tSNE analysis of multiplex qPCR from 168 epicardial cells (P0, Ad and $\mathrm{H}-\mathrm{Ad}$ ). Genes displayed are the most differential expressed genes corresponding to each cluster and are color-coded according to the to the physiological state. C. Violin plot of genes corresponding to the major epicardial derived lineages (Epic: epicardium, Sc: Stromal cells, Ec: endothelial cells, Smc: smooth muscle cells) of Pw1/Peg3 and of metabolic pathways from a total of 186 cells analyzed. D. Diffusion map (pseudo-time analysis) of Sc, Ec, and Smc populations based on single cell gene expression. Color-code according to the cell type (top panel) and according to the physiological state (bottom panel). E17.5: embryonic day 17.5, P0: postnatal day 0, Ad: Adult, H: Hypoxia, Epic: epicardium, Ec: endothelial cell, Smc: smooth muscle cell, Strc: stromal cells.

Figure 4. In vitro hypoxia maintains growth and cell fate potentials to Gp38+PW1+ epicardial cells. A. Schema of the in vitro experiment: cell sorting (Gp38 ${ }^{+} P w 1-\mathrm{FDG}^{+}$cells) with a purity of more than $90 \%$ from $\mathrm{E} 17.5, \mathrm{P0}$, adult (Ad) and in vivo hypoxia-primed adult $(\mathrm{H}-\mathrm{Ad})$ hearts. Freshly sorted cells were cultured from D0 to D8 either in normoxia $\left(21 \% \mathrm{O}_{2}\right)$ or hypoxia $\left(\begin{array}{ll}1 \% & \mathrm{O}_{2}\end{array}\right)$. B. Frequency of colonies (1000 cells/well) cultured either under normoxia or hypoxia in vitro condition and the respective brightfield pictures of the cobblestone-like Gp38+ colonies. C. Immunolabeling shows the colonies keep the Gp38 and Pw1 expression similar to their initial ex vivo profile (clonogenicity). D. Immunolabeling of the cell cycle makers Ki67 and pH3 highlights the proliferative profile (green arrowheads) of colony of Gp38+PW1+ cells (self-renewal). E. Epicardial-derived and stromal cell markers (Gp38 and PDGFRa) are observed in the main cell fraction of the colony. F. Smooth muscle cell markers ( $\alpha$ SMA and SM22 $\alpha$ ) are observed in the majority of the cells composing the Gp38+ colony. G. Endothelial marker Flk1, but not CD31, is observed to be expressed in 


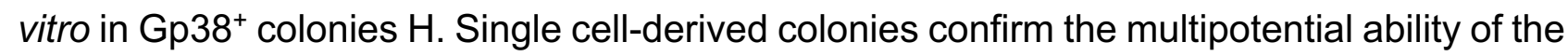
Gp38+PW1+ cells to differentiate into smooth muscle, stromal and immature endothelial cells. Scale bar: $100 \mu \mathrm{m}$. All nuclei were counterstained with DAPI. Statistical significance was determined by Mann-Whitney test. ${ }^{* * *} p<0.001,{ }^{* *} p<0.01,{ }^{* *} p<0.05$. BF: Brightfield, E.17.5: embryonic day 17.5, P0: postnatal day 0, Ad: Adult.

Figure 5. In vivo hypoxia-priming confers/restores the CFU ability in adult epicardial cells. A. Limiting dilution assay to determine (at the maximum likelihood parameter) the frequency of stem cells (CFU) within the $\mathrm{Gp} 38^{+} \mathrm{PW} 1^{+}$cell population. The graph shows the number of negative wells (non-response) for the growth of a colony and the CFU probability (E17.5 - 1/40, P0 - 1/25, Ad - 1/324 and H-Ad - 1/100). B. Gp38+ cells form under hypoxia a cobblestone structure typical of epithelial structure colony $(\mathrm{H}-\mathrm{Ad})$, similarly to that observed in developing epicardium (E17.5 and P0). C. Immunolabelling of the hypoxia-primed adult

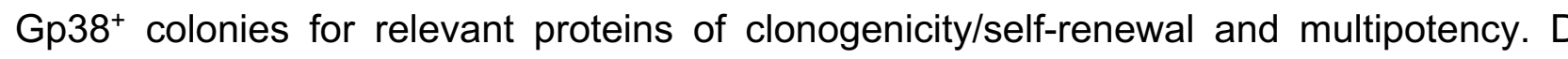
Comparison of the Gp38 and PW1 protein expression (clonogenicity/self-renewal) in P0, adult (normoxia and hypoxia). E. Comparison of the Ki67 and pH3 cell cycle protein (selfrenewal) in P0, adult (normoxia and hypoxia). F. Comparison of the aSMA, SM22a, PDGFRa and Flk1 protein expression (multipotency) in P0, adult (normoxia and hypoxia).

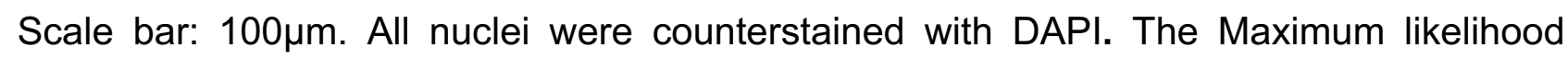
estimation (MLE) test (ELDA assay) was used for the statistical determination of the CFU values for each stage of $\mathrm{Gp} 38^{+}$cells with a $p<0.0001$. The line in the box plot represents the median. Statistical significance was determined by one-way ANOVA (Kruskal-Wallis test) with uncorrected Dunn's test. ${ }^{* * *} p<0.0001,{ }^{* *} p<0.01,{ }^{*} p<0.05$. P0: postnatal day 0 , Ad: Adult, H: Hypoxia. 
Figure 6. Proposed model for hypoxia activation of the adult murine epicardium to a progenitor cell function and multipotency. Epicardium is an active reservoir of progenitor cells that gives rise to coronary vasculature and stroma cells during perinatal life. The adult mammalian epicardium is a heart resident progenitor niche that maintains PW1 and WT1 expression, and a hypoxic environment. Hypoxia-primed epicardium activation induces a progenitor profile and shows multilineage differentiation ability, including the stromal, smooth muscle and endothelial lineage fates. 


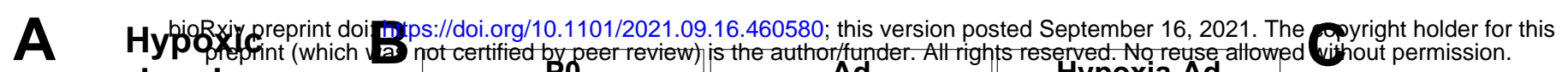
chamber
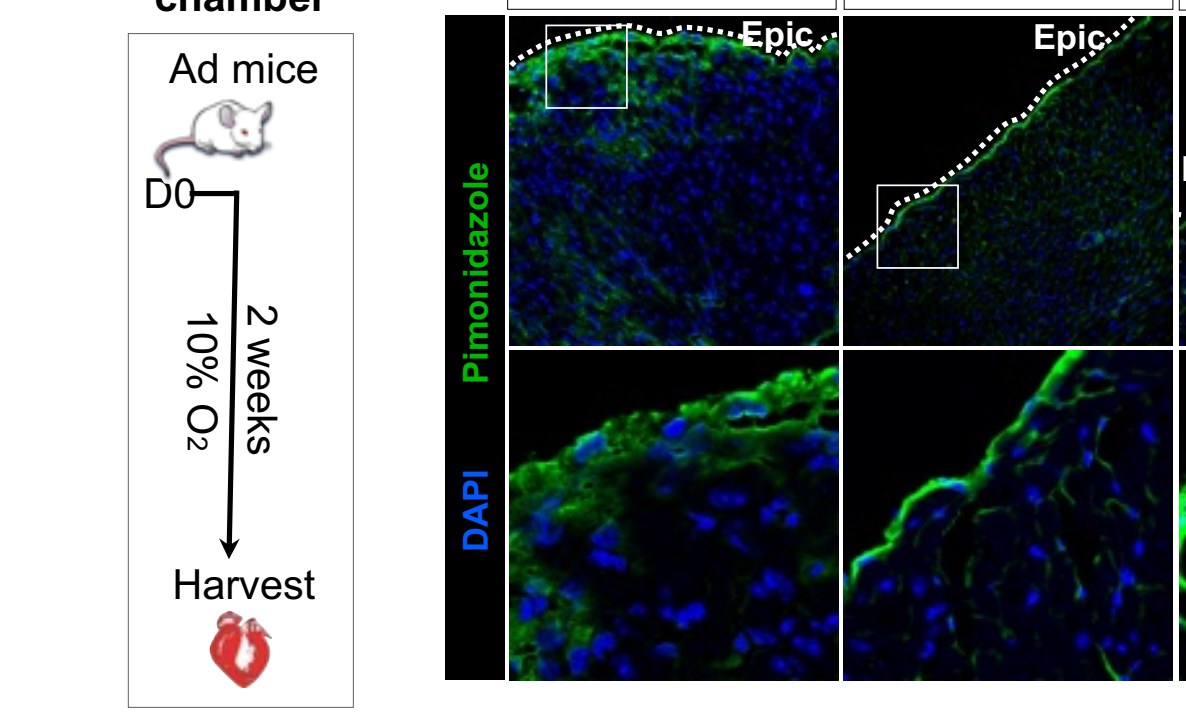

Hypoxia-Ad

Fig1

D
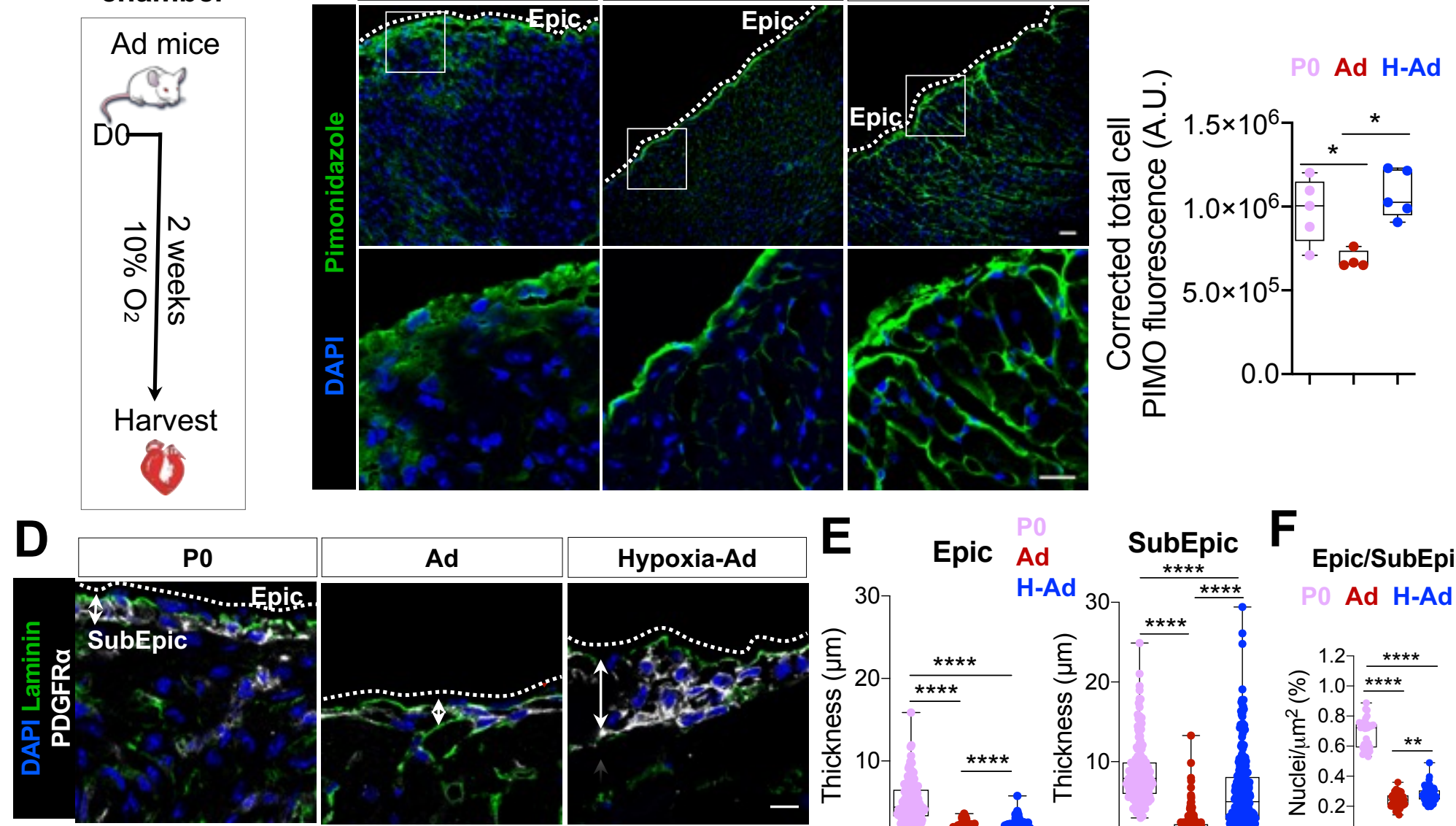

Hypoxia-Ad
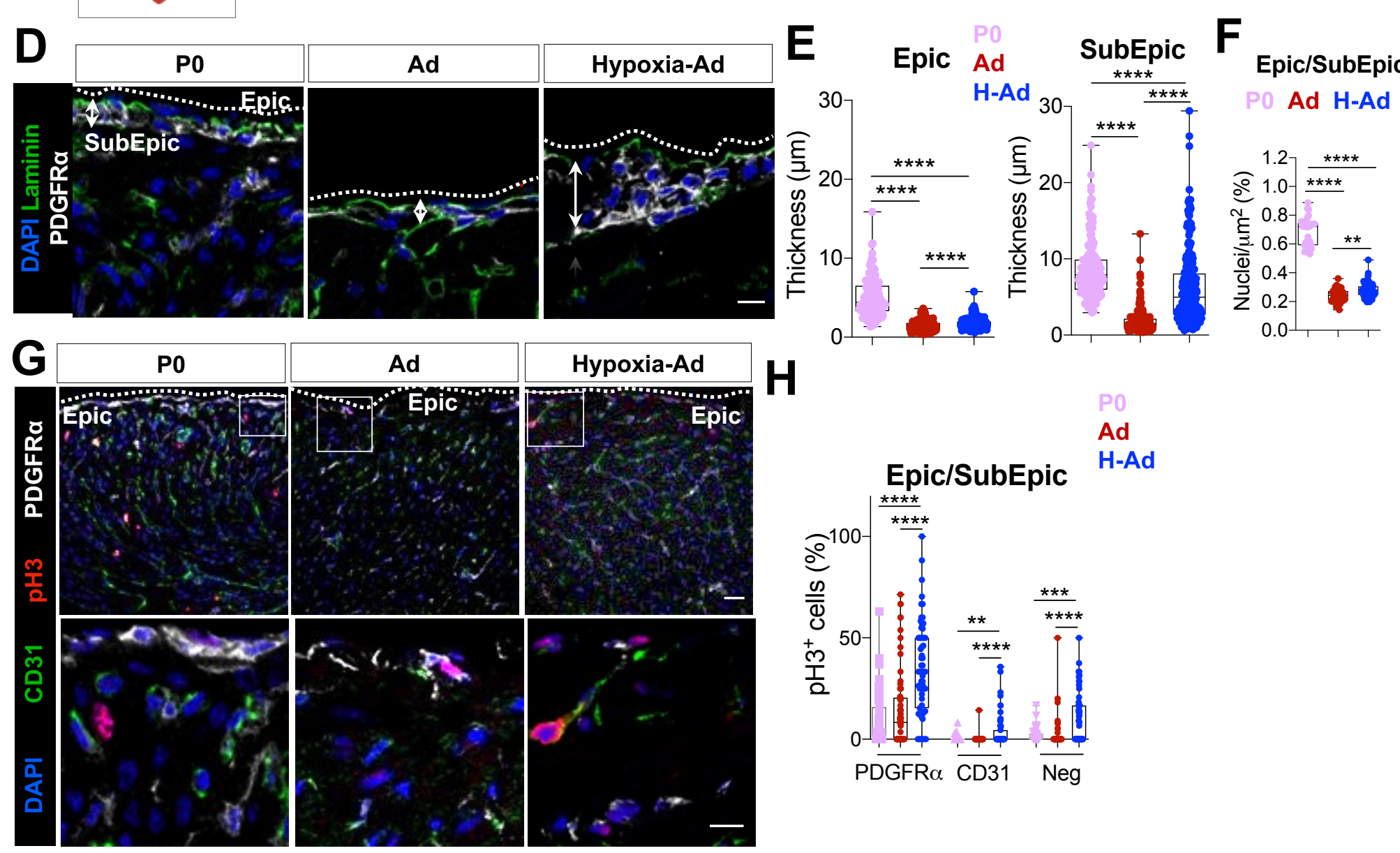

\section{H}
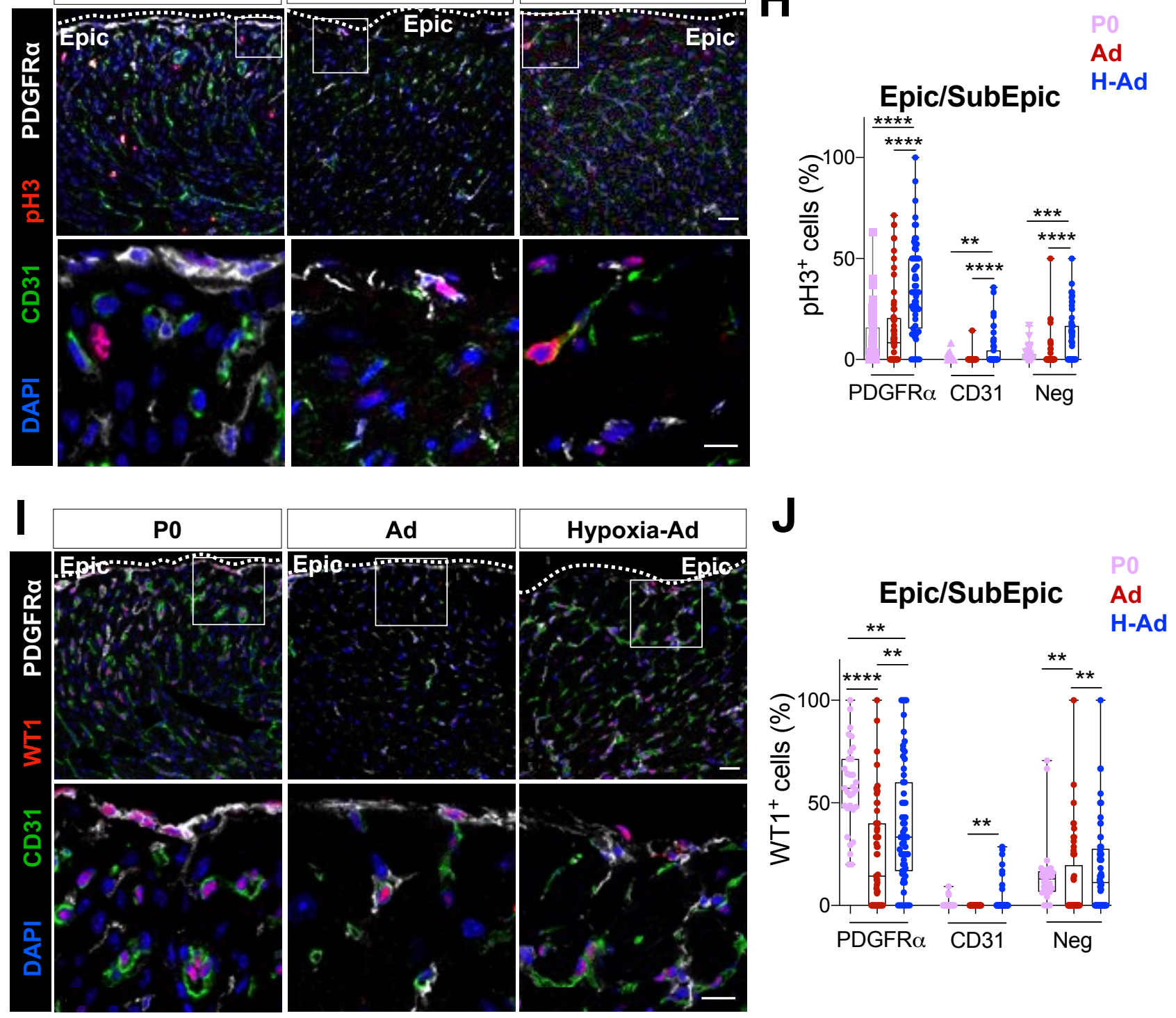
A Ad Hypoxia-Ad Live cells/TER119/CD45/CD11b-
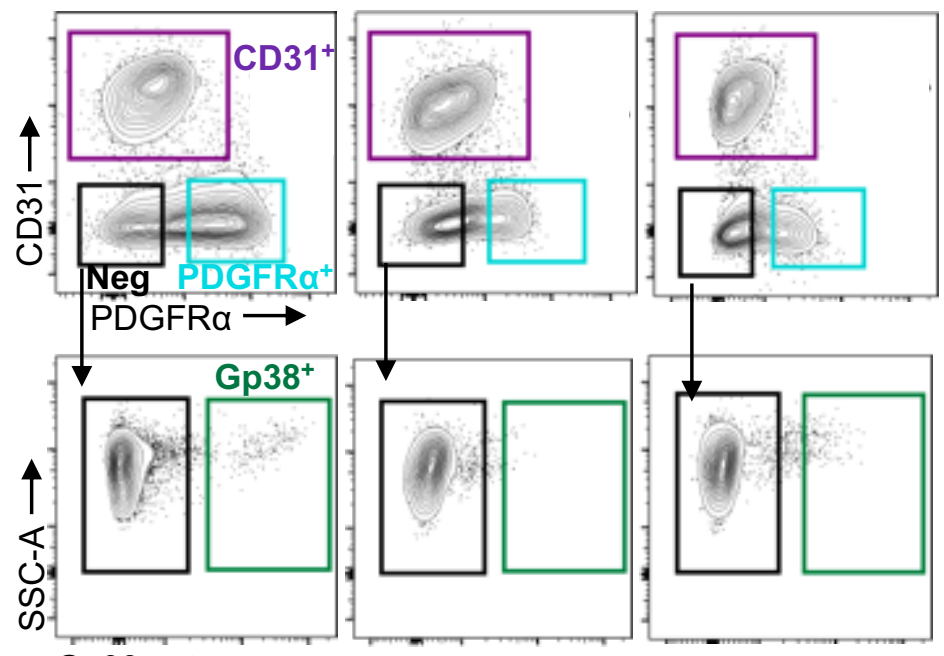

$\mathrm{Gp3} 8 \longrightarrow$

B

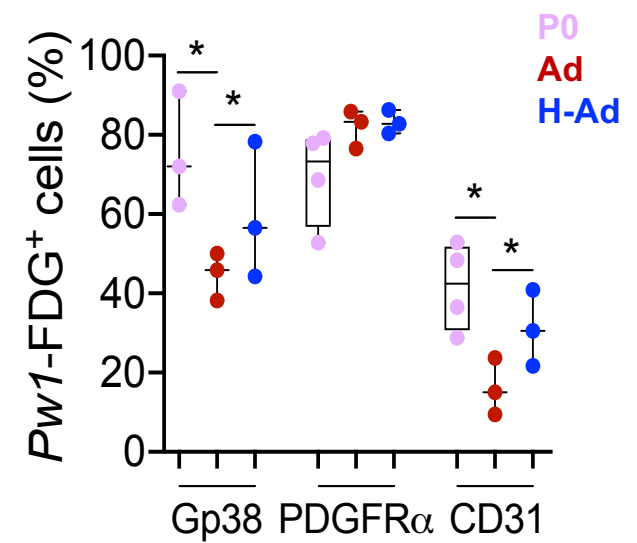

E

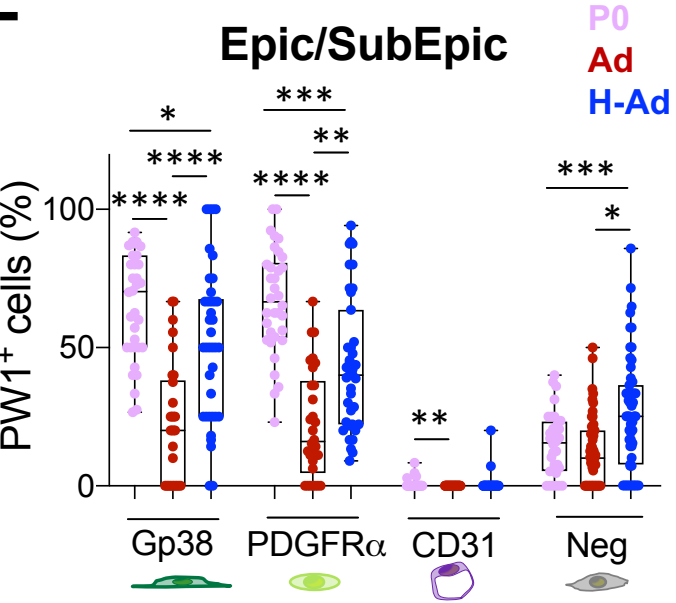

$\mathbf{F}$

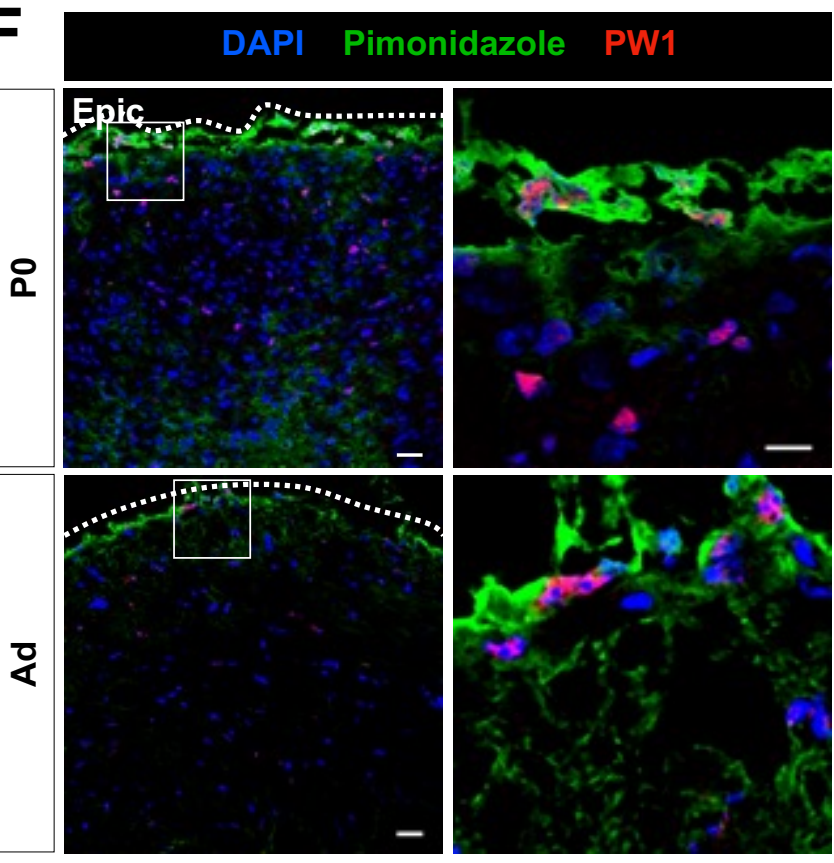

C $\begin{array}{cccc}\text { DAPI } & \text { Gp38 } & \text { PW1 } & \text { PDGFRa }\end{array}$

요

¿
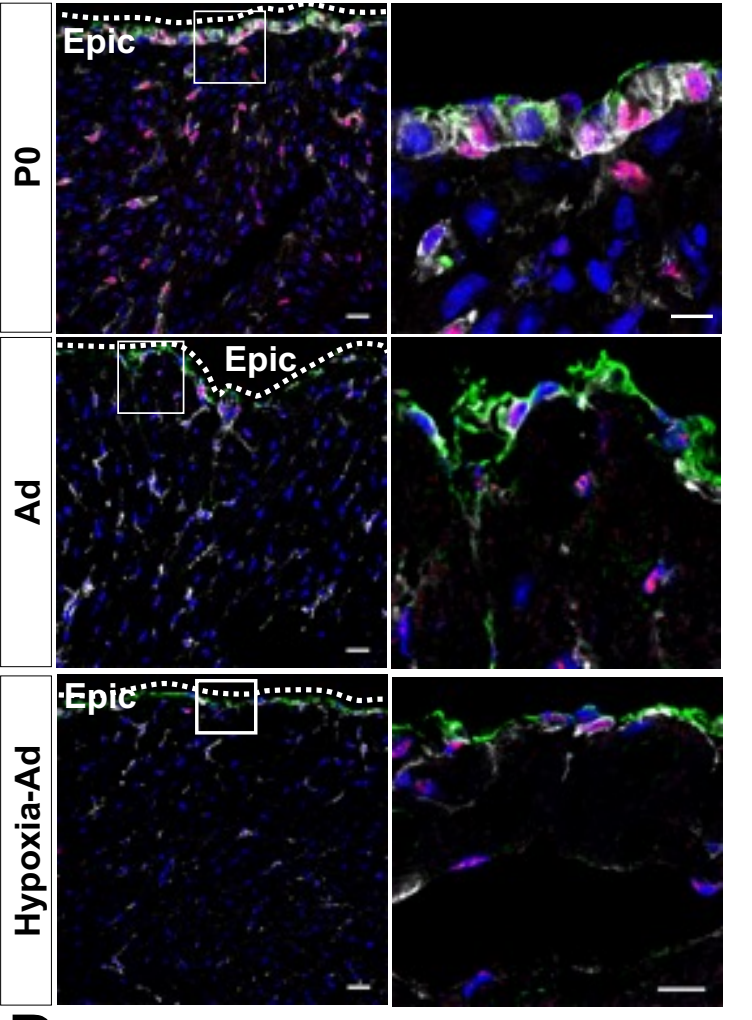

D

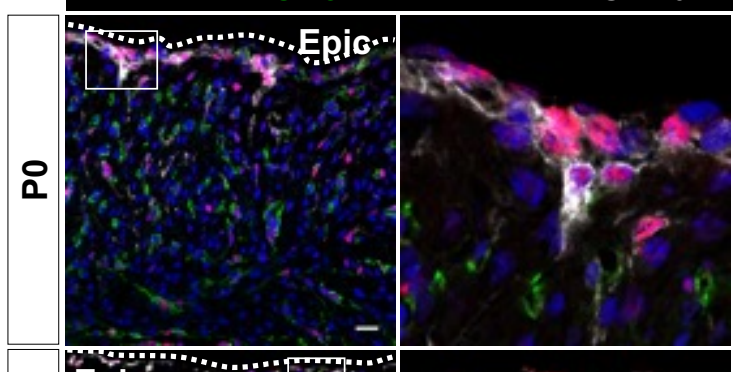

우

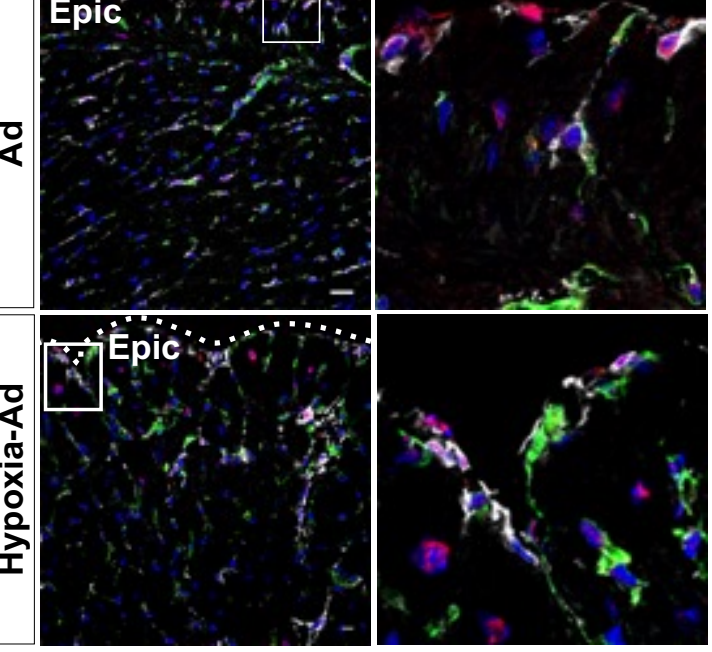

$G$

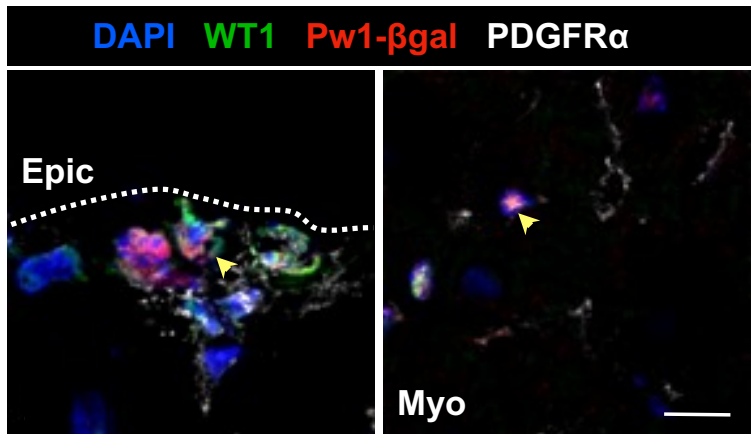


A
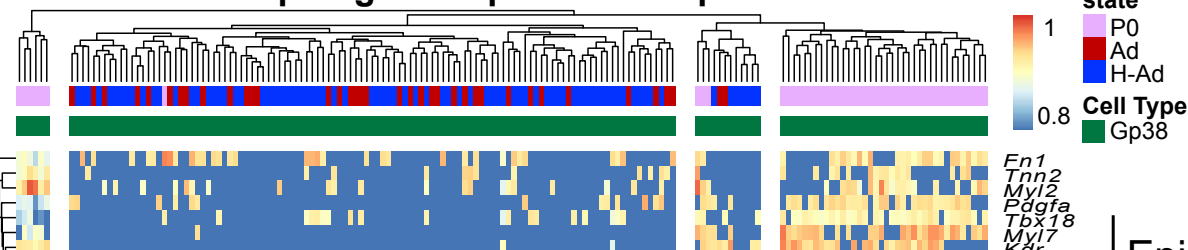

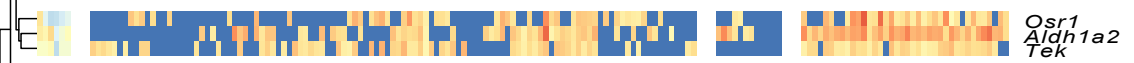

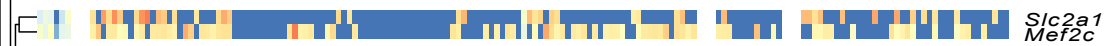
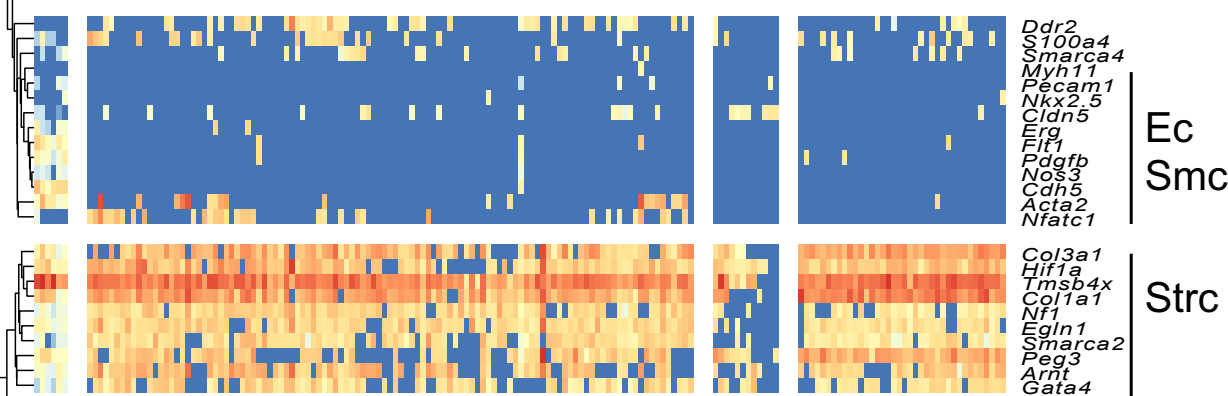

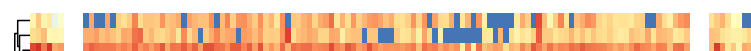

\section{E}

E

\section{단}

\section{E}

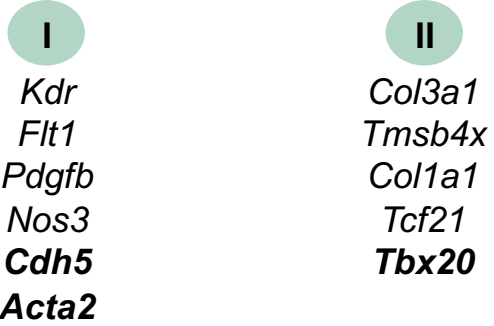

C

$$
\text { 늠 }
$$

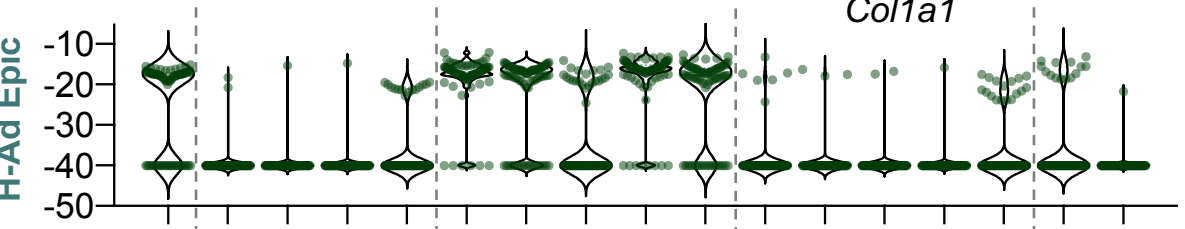
8

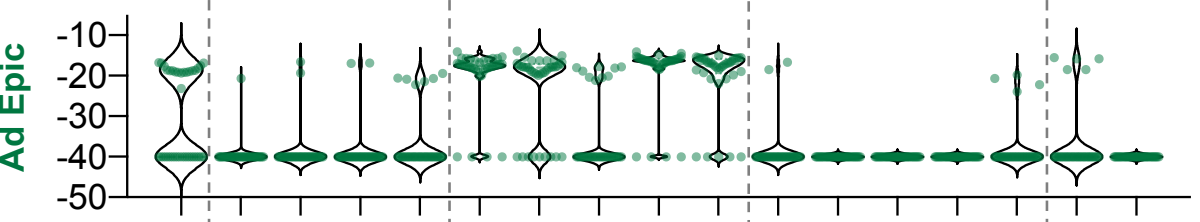

$\frac{-0}{2}$

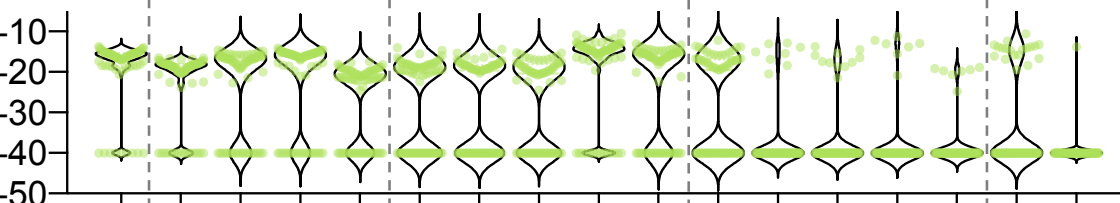

U

\section{$-10-$}

बब

$-40$

$-50$

-10
-20
-30
-40
-50

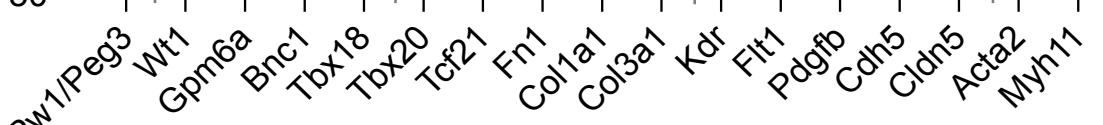

Gp38+ cells
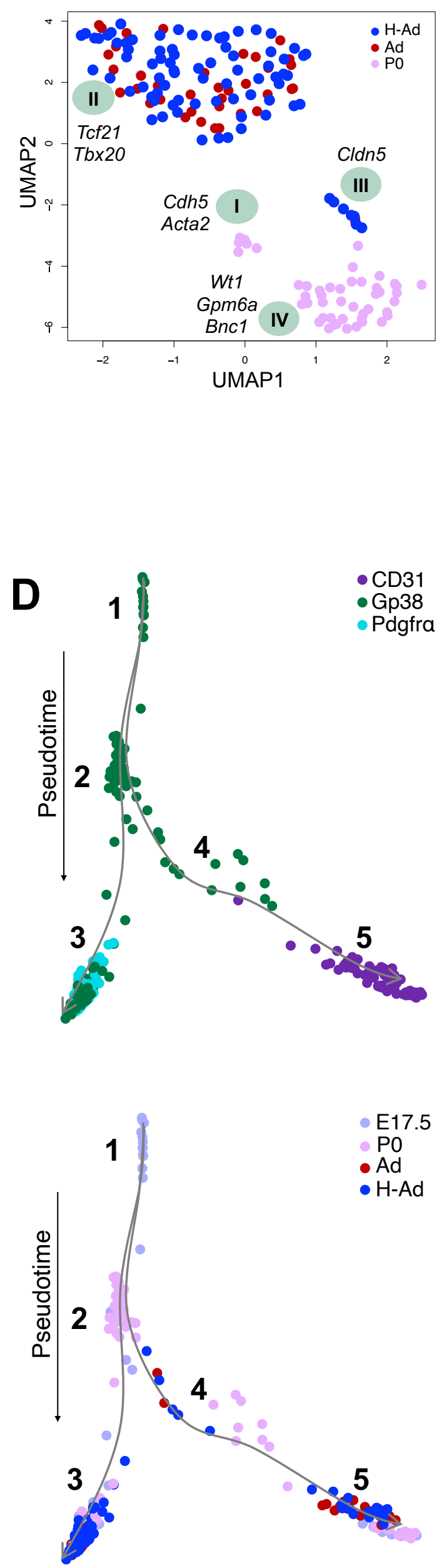


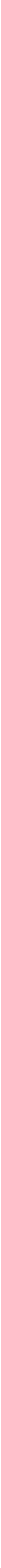


A

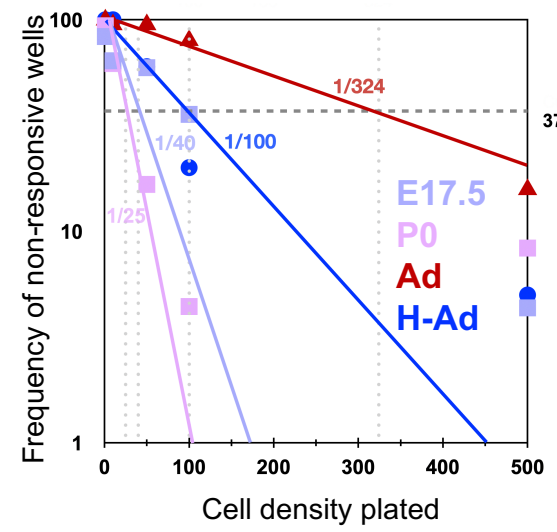

C
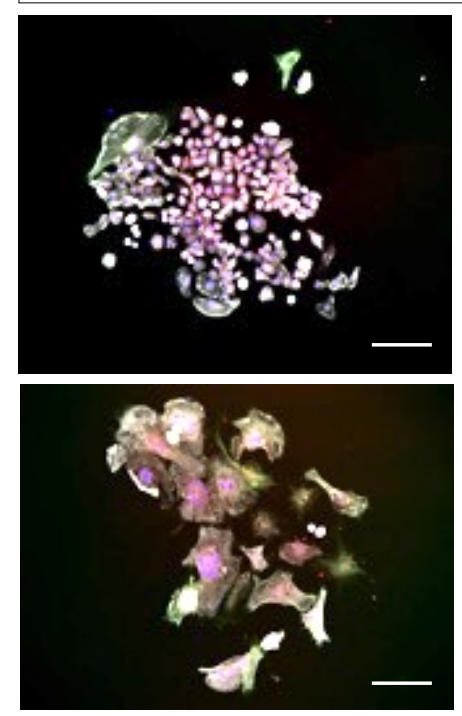

Merge
B

PO

H-Ad

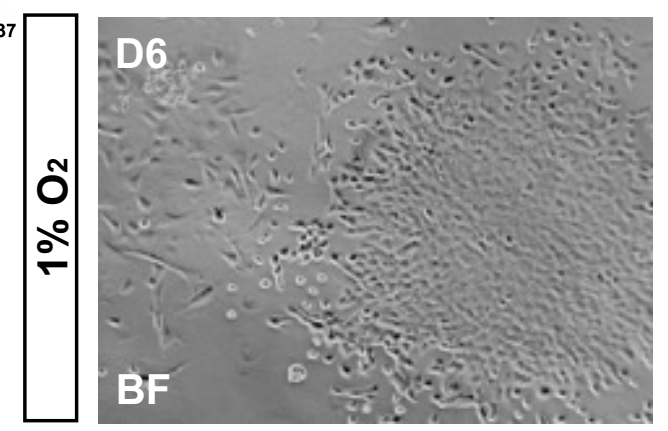

H-Ad
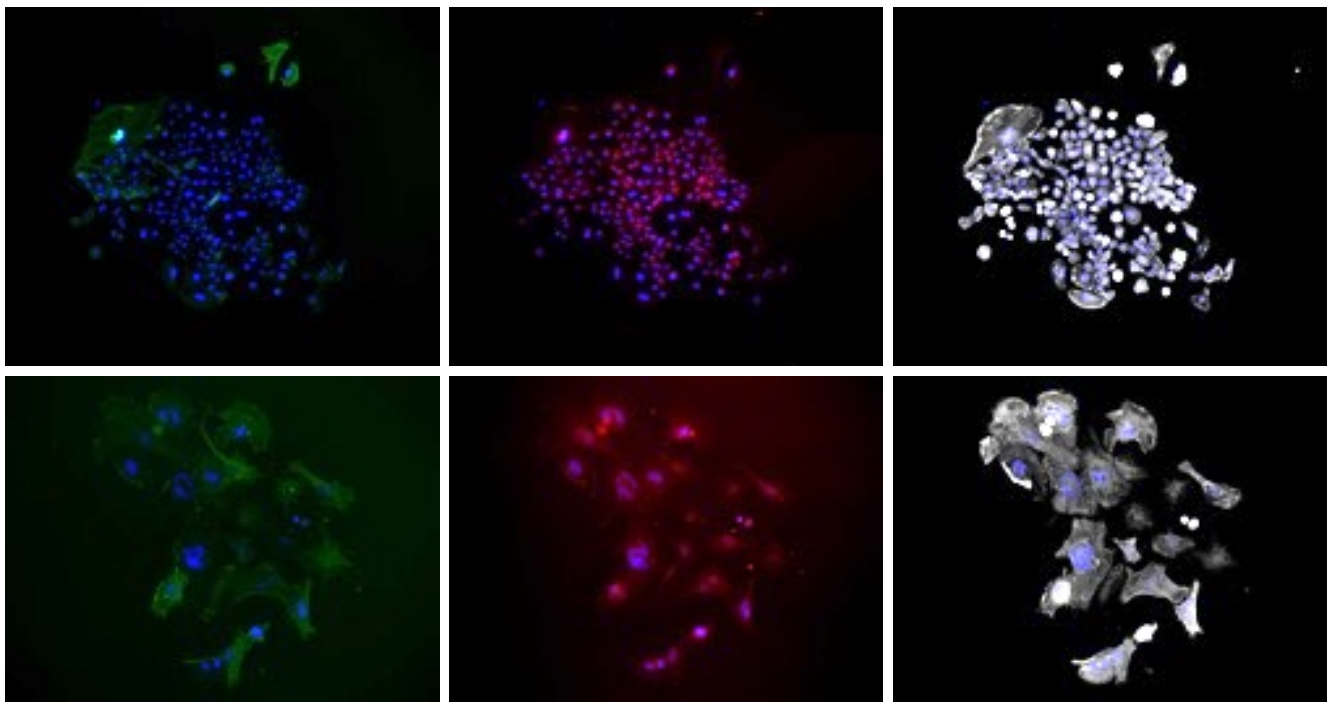

DAPI aSMA

DAPI Gp38

DAPI FIk1

D

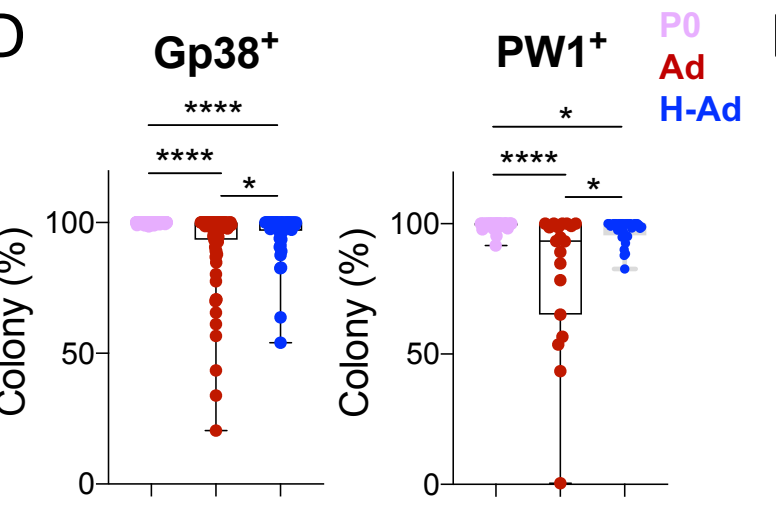

E $\quad \mathrm{Ki}^{\mathbf{6}} \mathbf{7}^{+}$

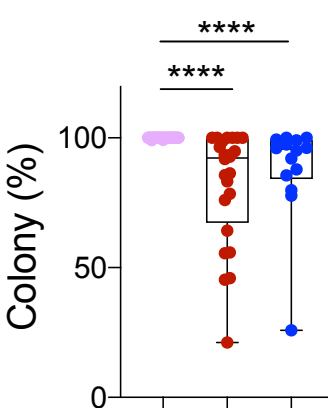

$\mathrm{pH}^{+}$

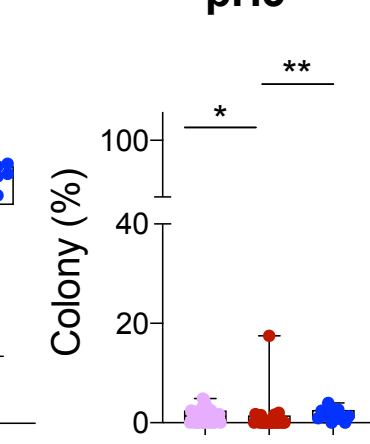

등

Ad H-Ad

F

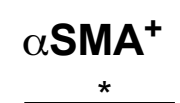

SM22 $\alpha^{+}$

PDGFR $\alpha^{+}$

Flk1 $^{+}$

* Ad

$\star * * *$

H-Ad

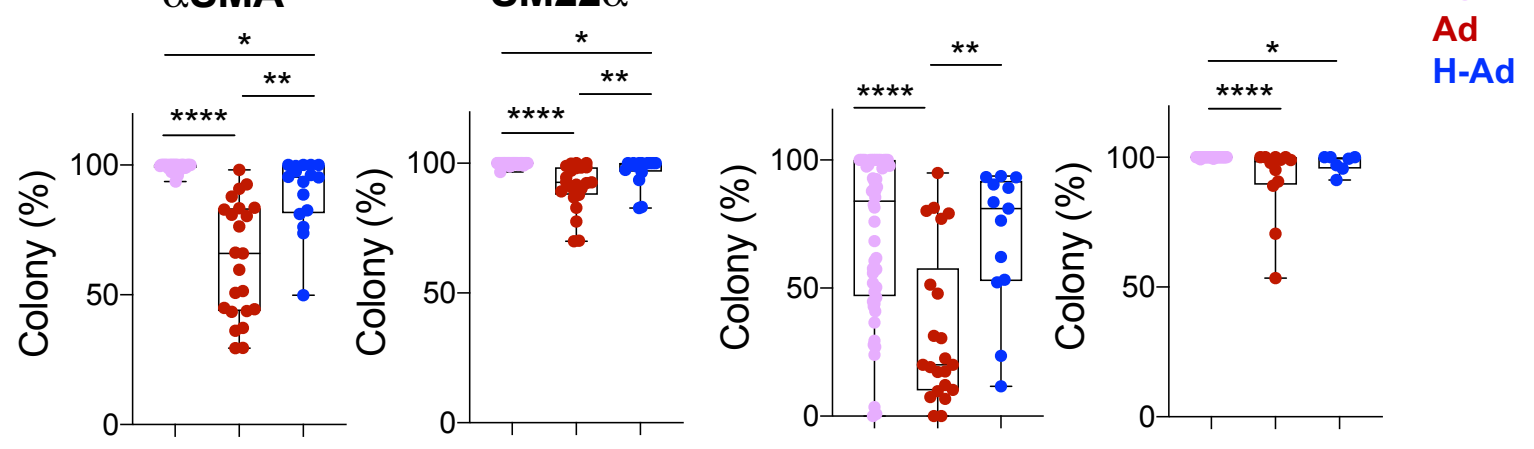




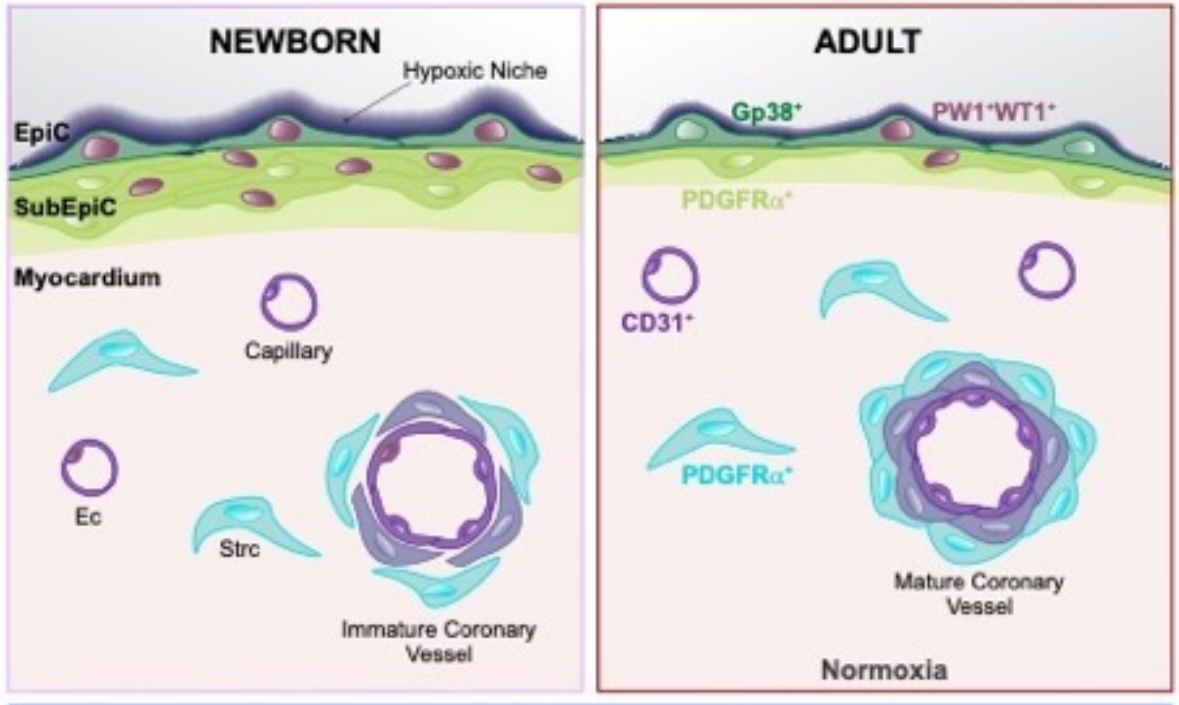

Fig6

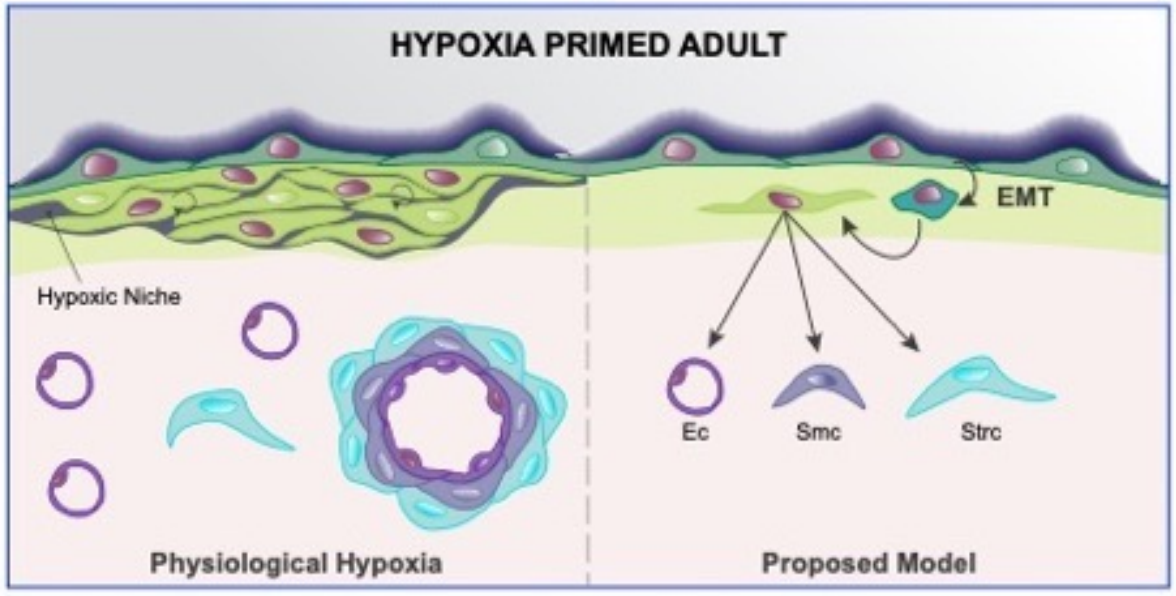


A
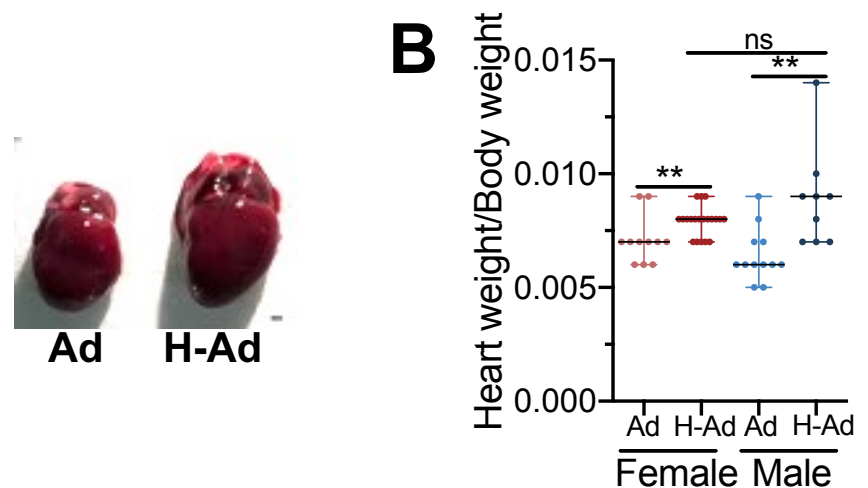

C
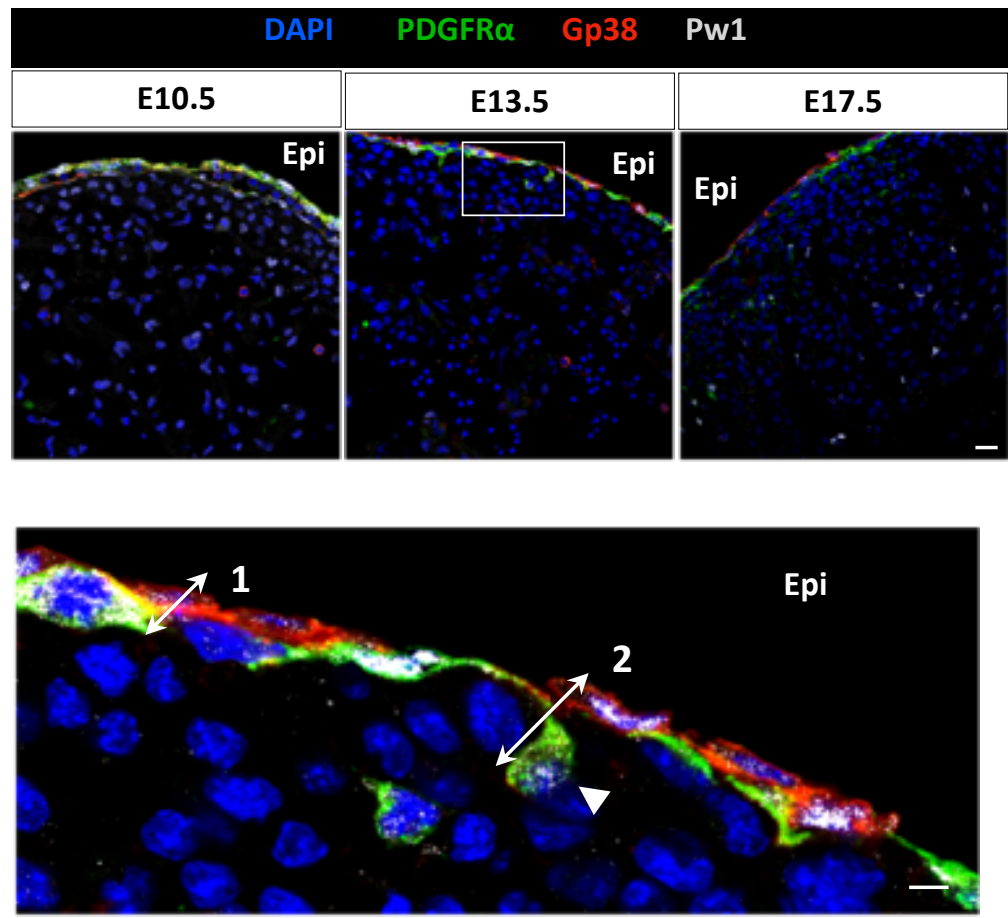

D

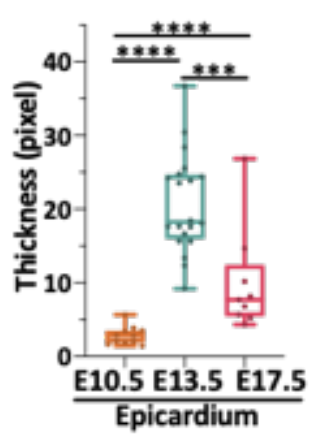

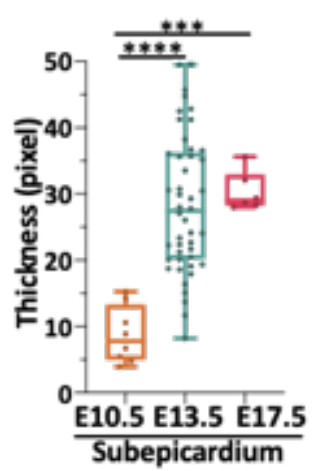


A
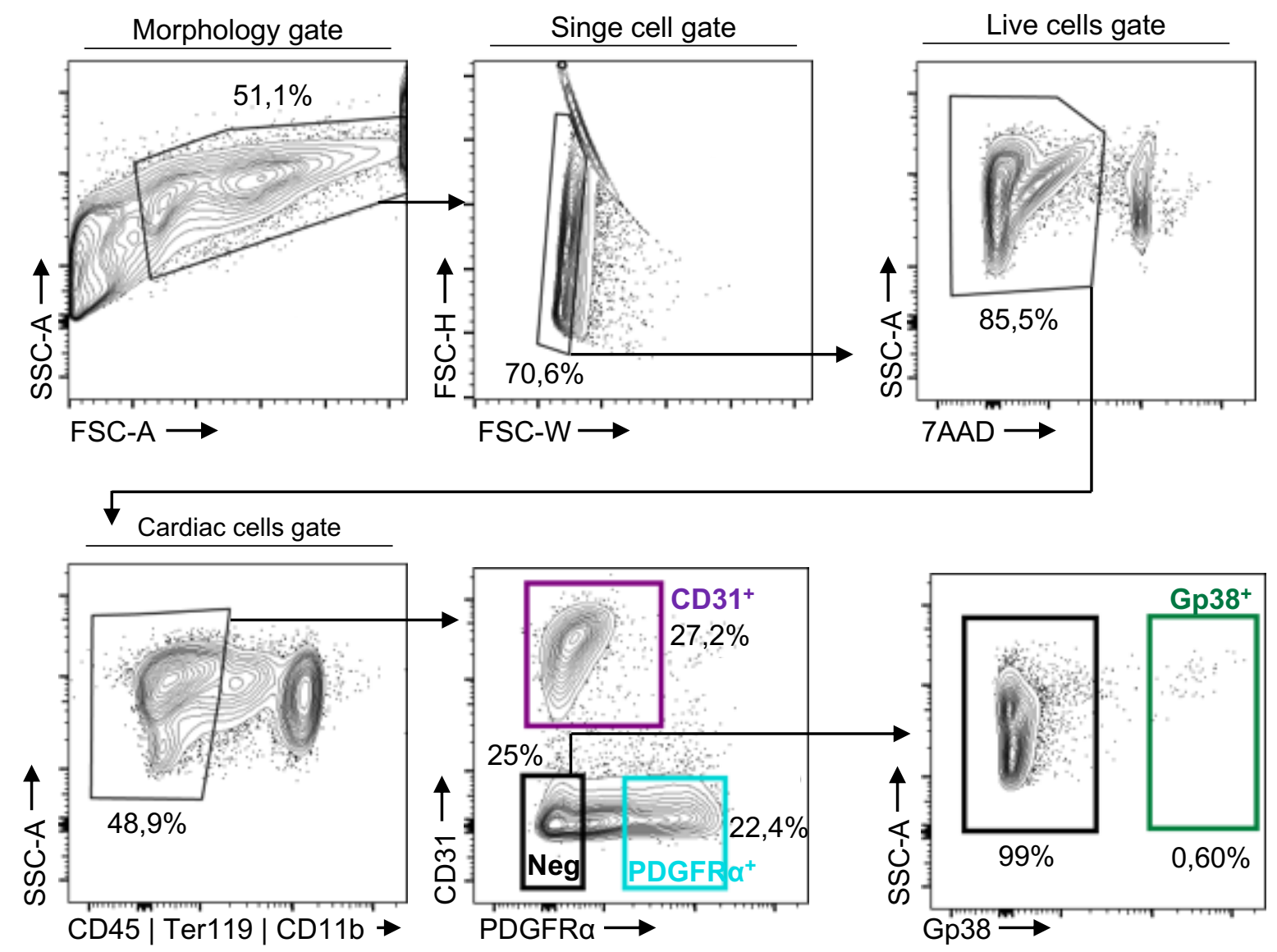

B
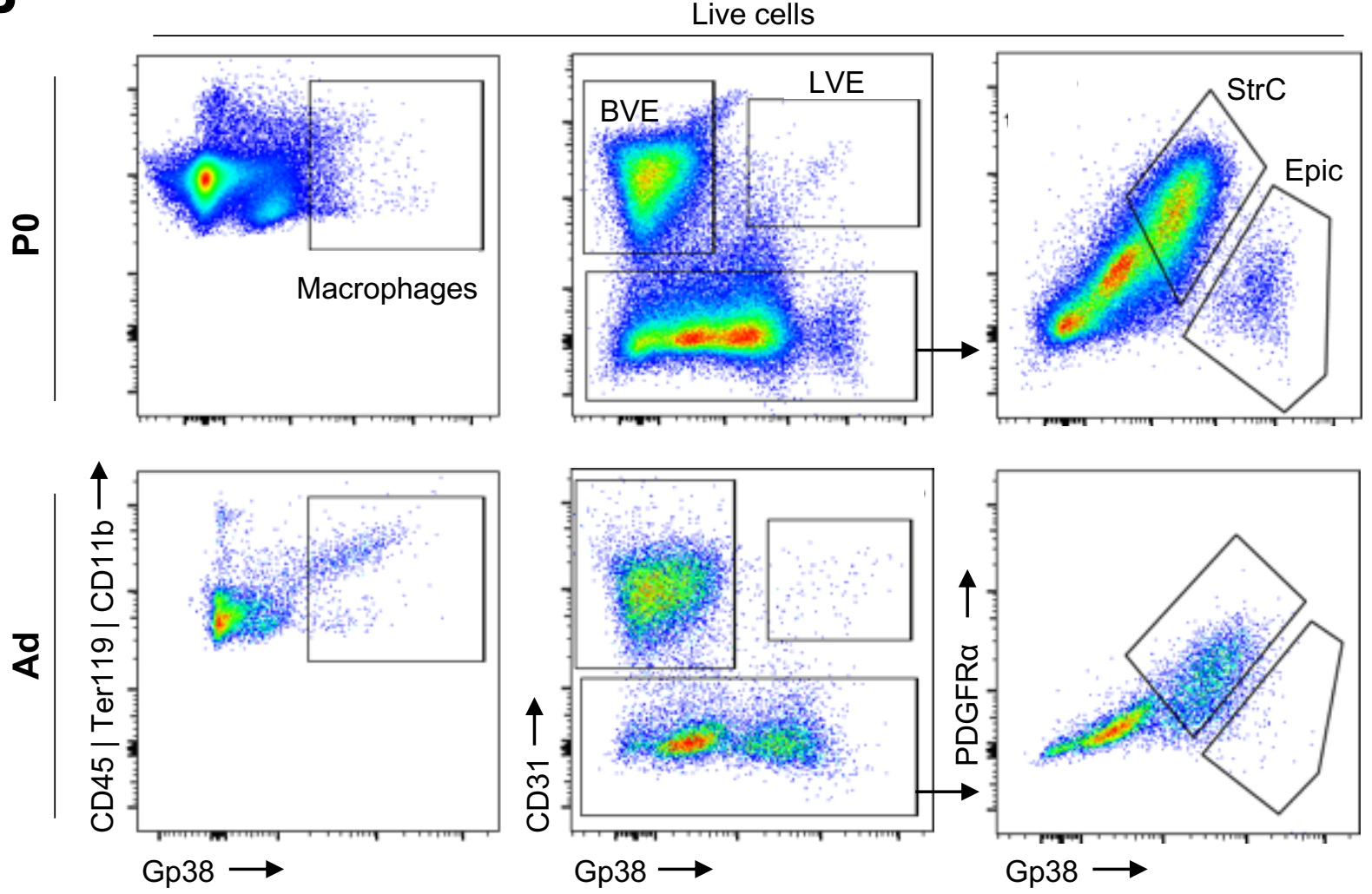
A

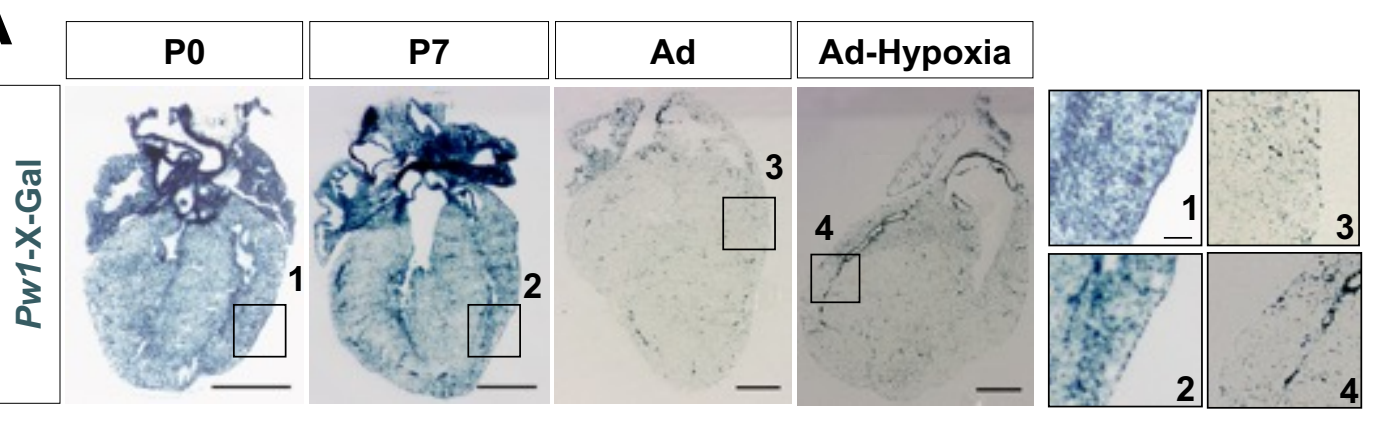

B

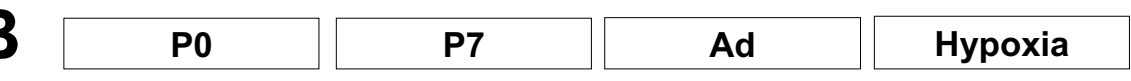

Live cells/TER119-/CD45/CD11 b-

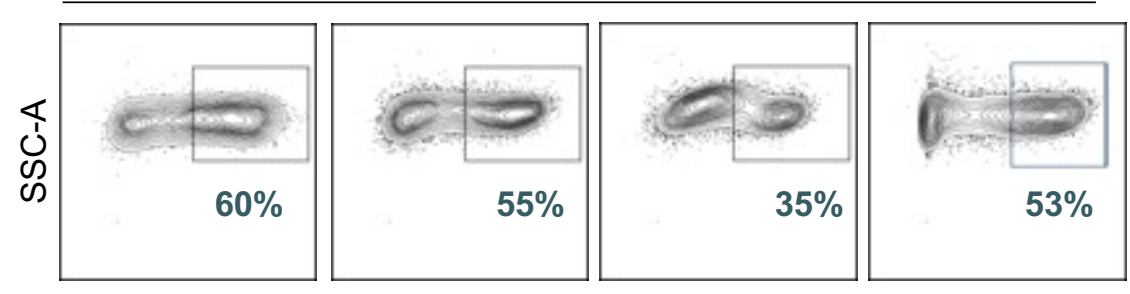

PW1-FDG $\longrightarrow$

C

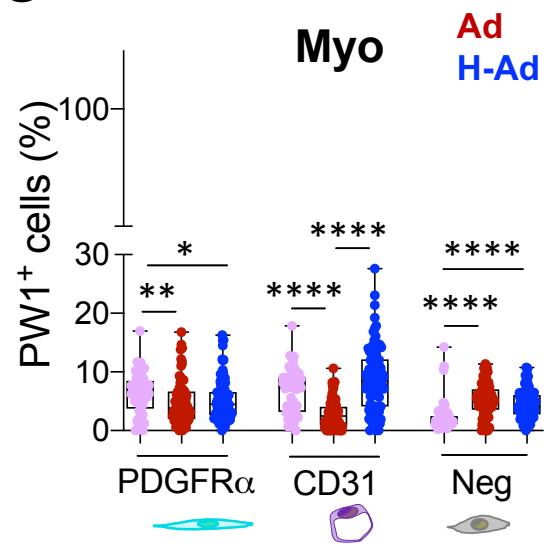

D

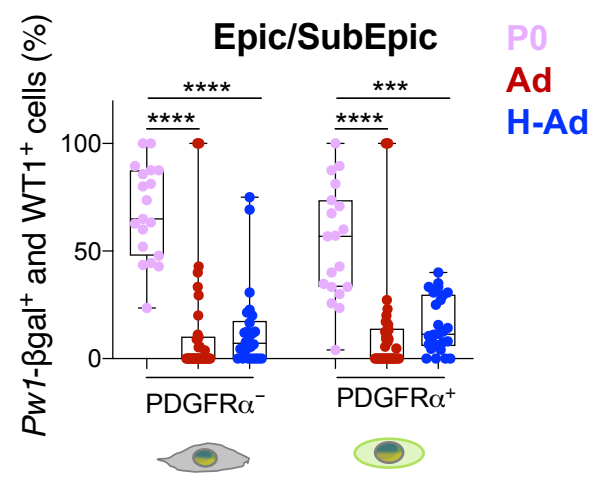


A

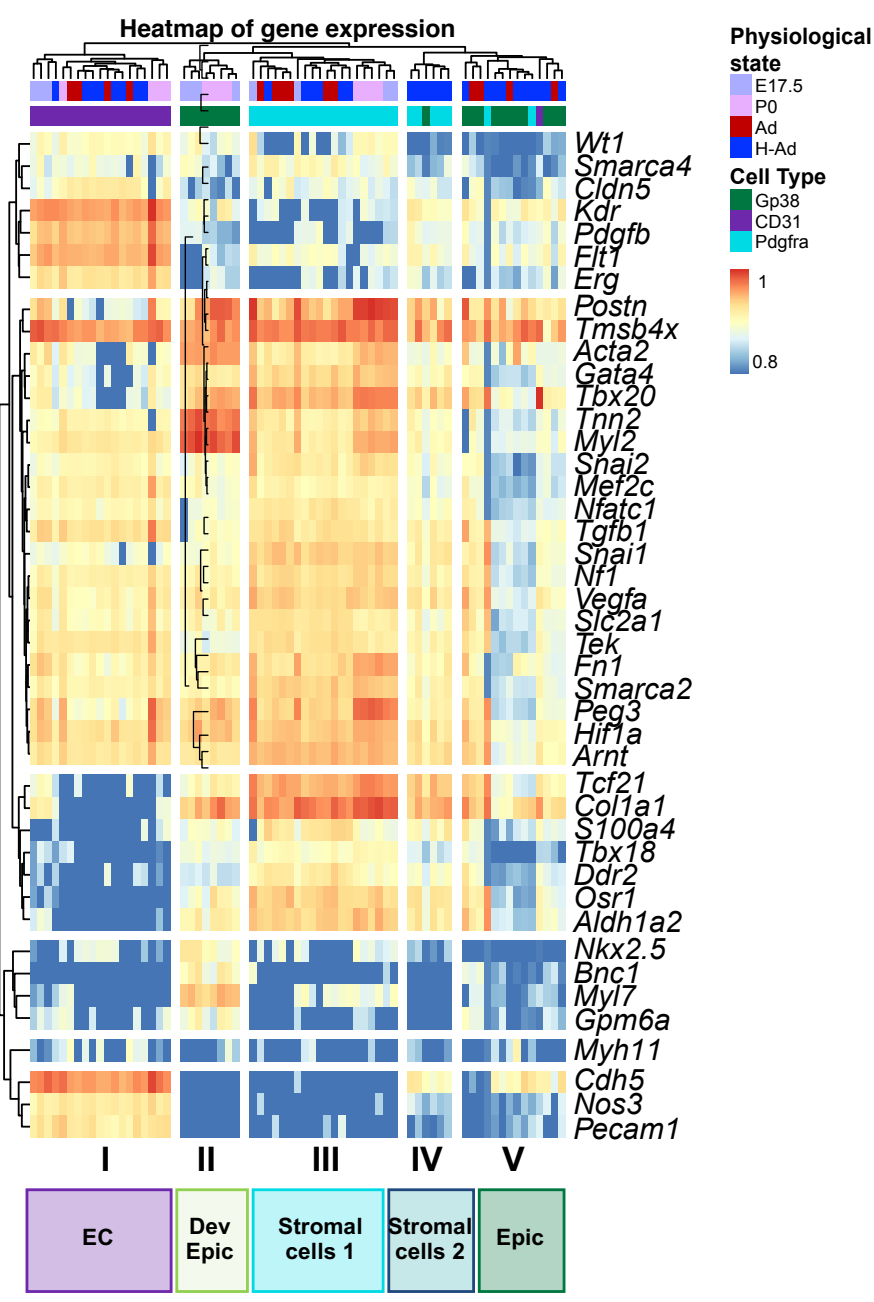

B
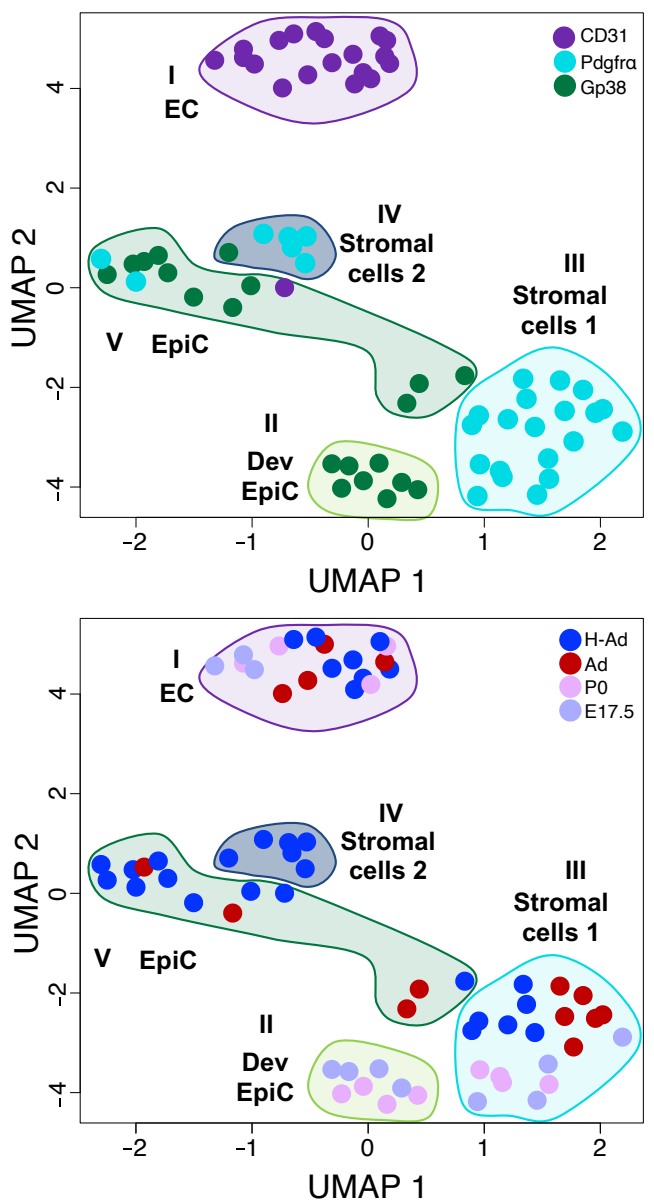


\section{Fig $S V$}

A

Heatmap of gene expression

1 Physiologica

State

E17.5
P0

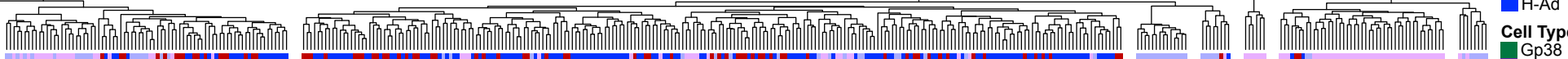

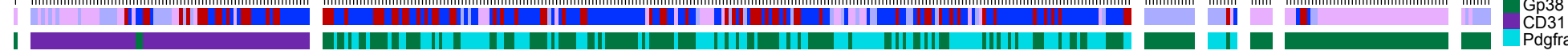

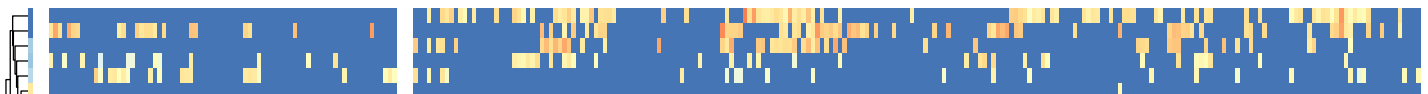

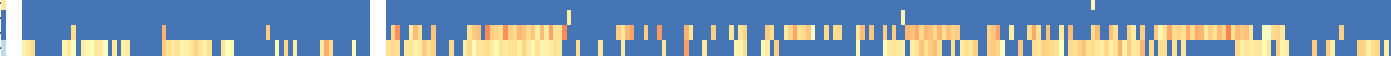
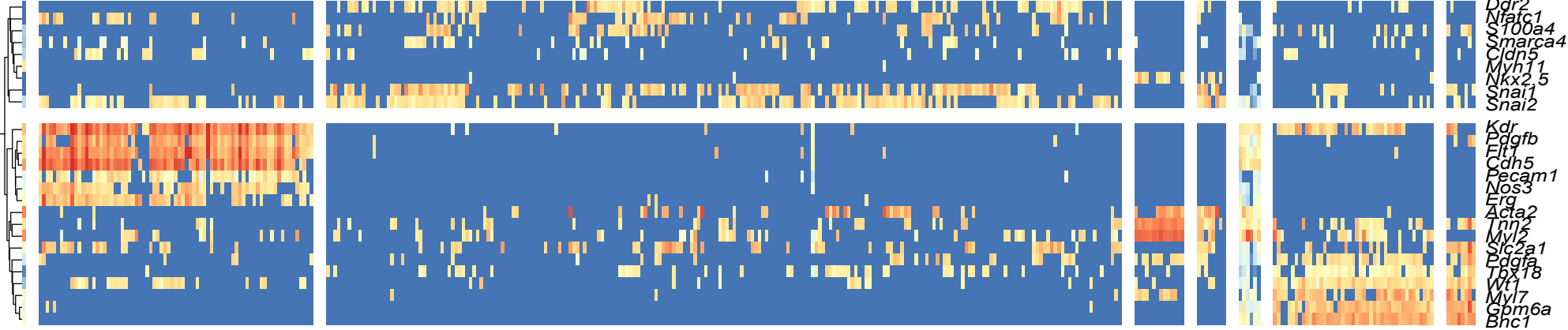

II II II Snaì

E RTH

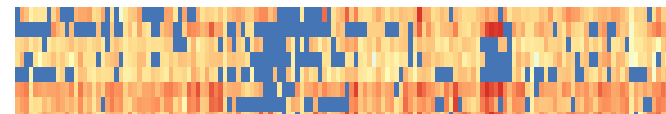

I I

th

-

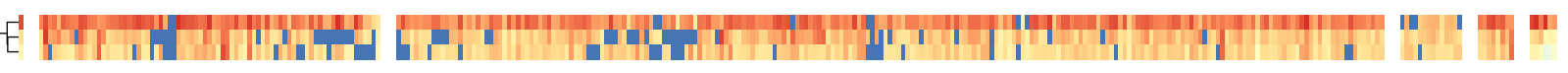

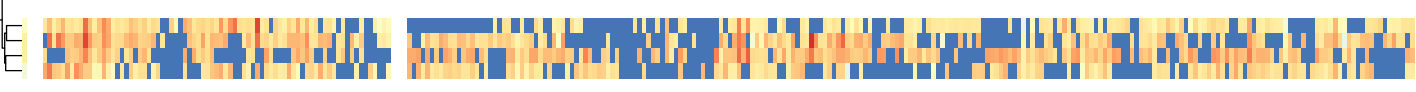

I

EC

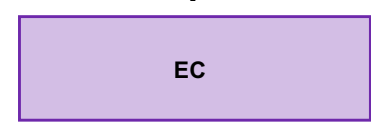

B

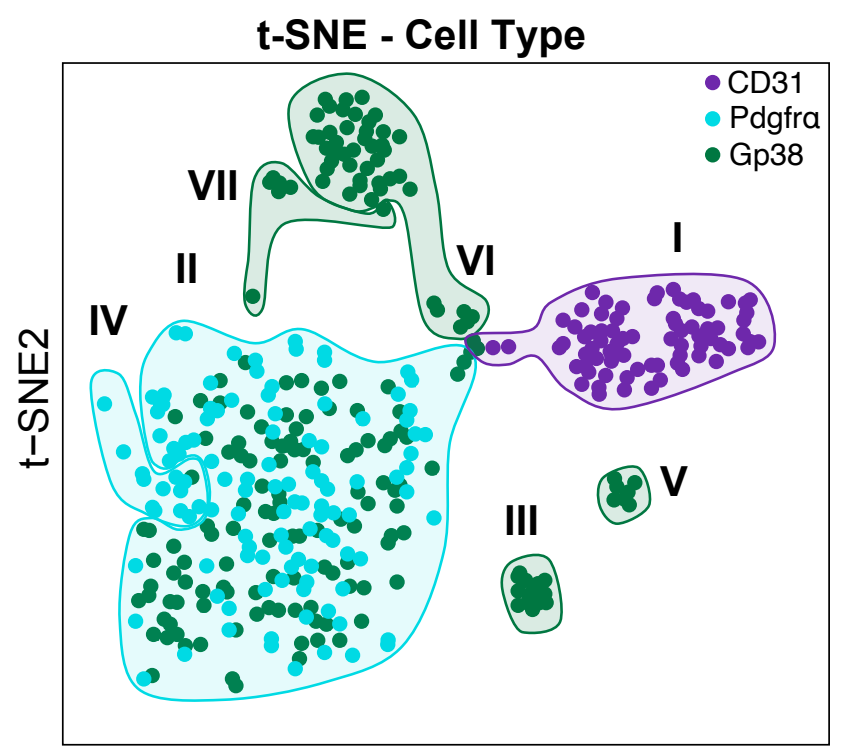

$\mathrm{t}-\mathrm{SNE} 1$
t-SNE - Physiological State

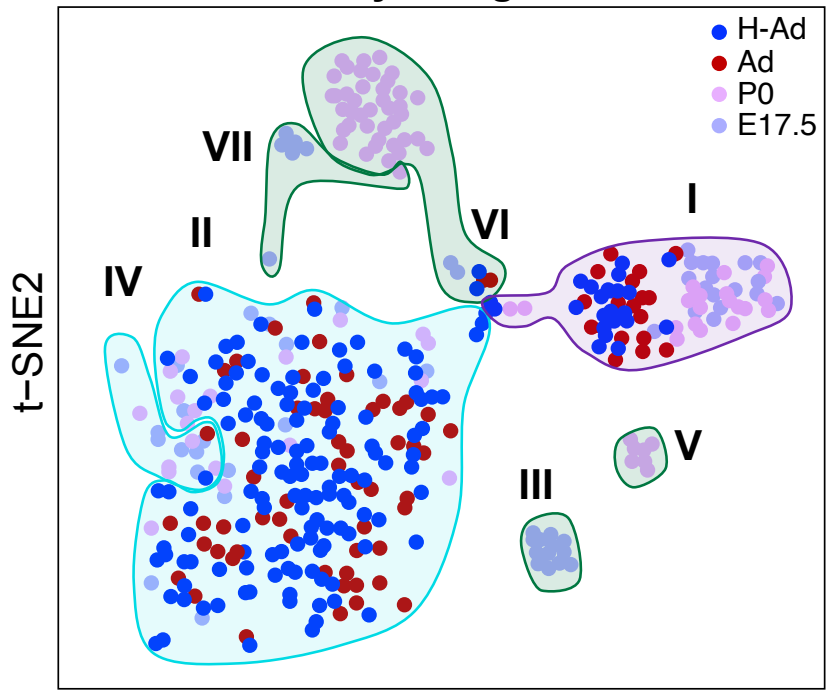

$\mathrm{t}-\mathrm{SNE} 1$ 


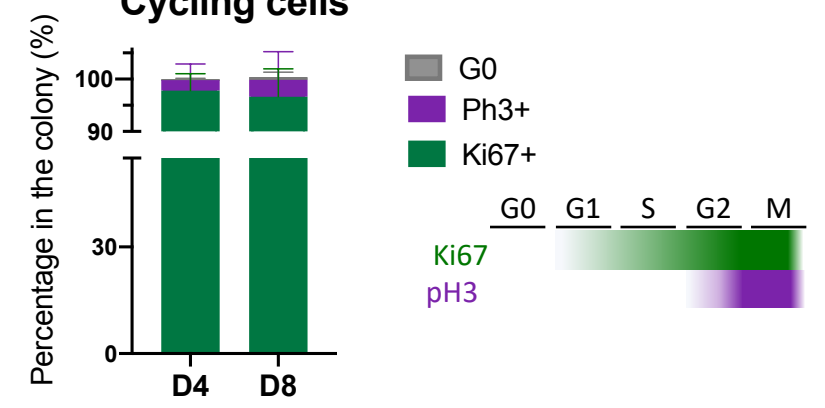

B
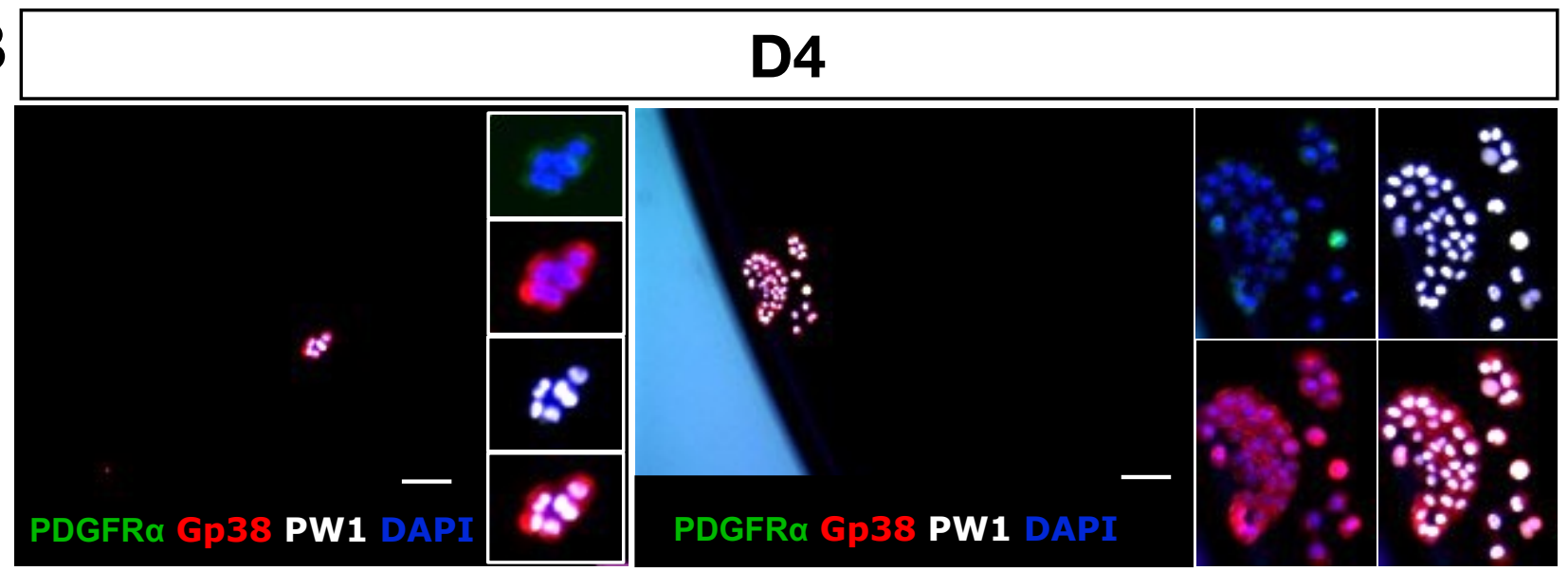

C
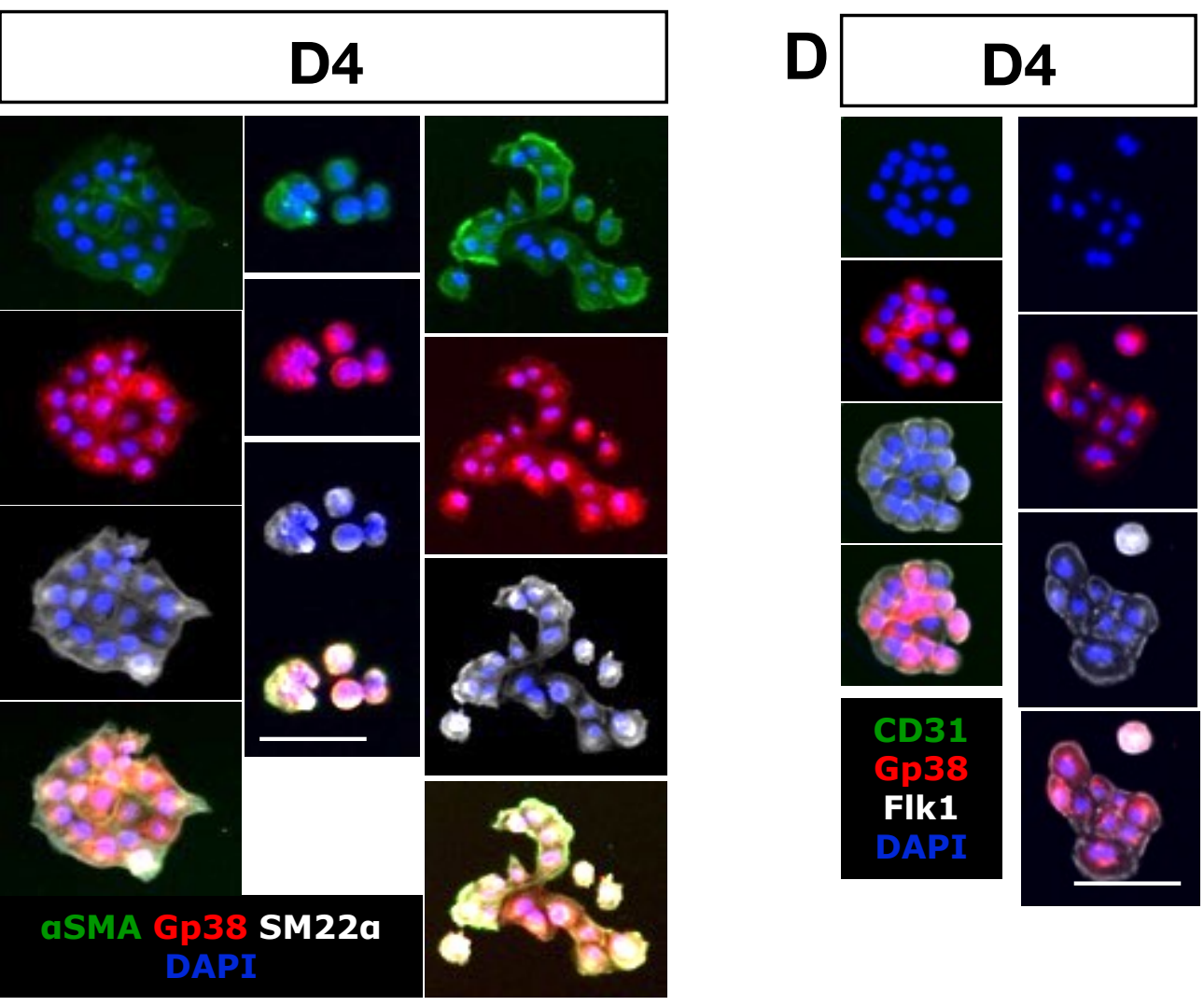


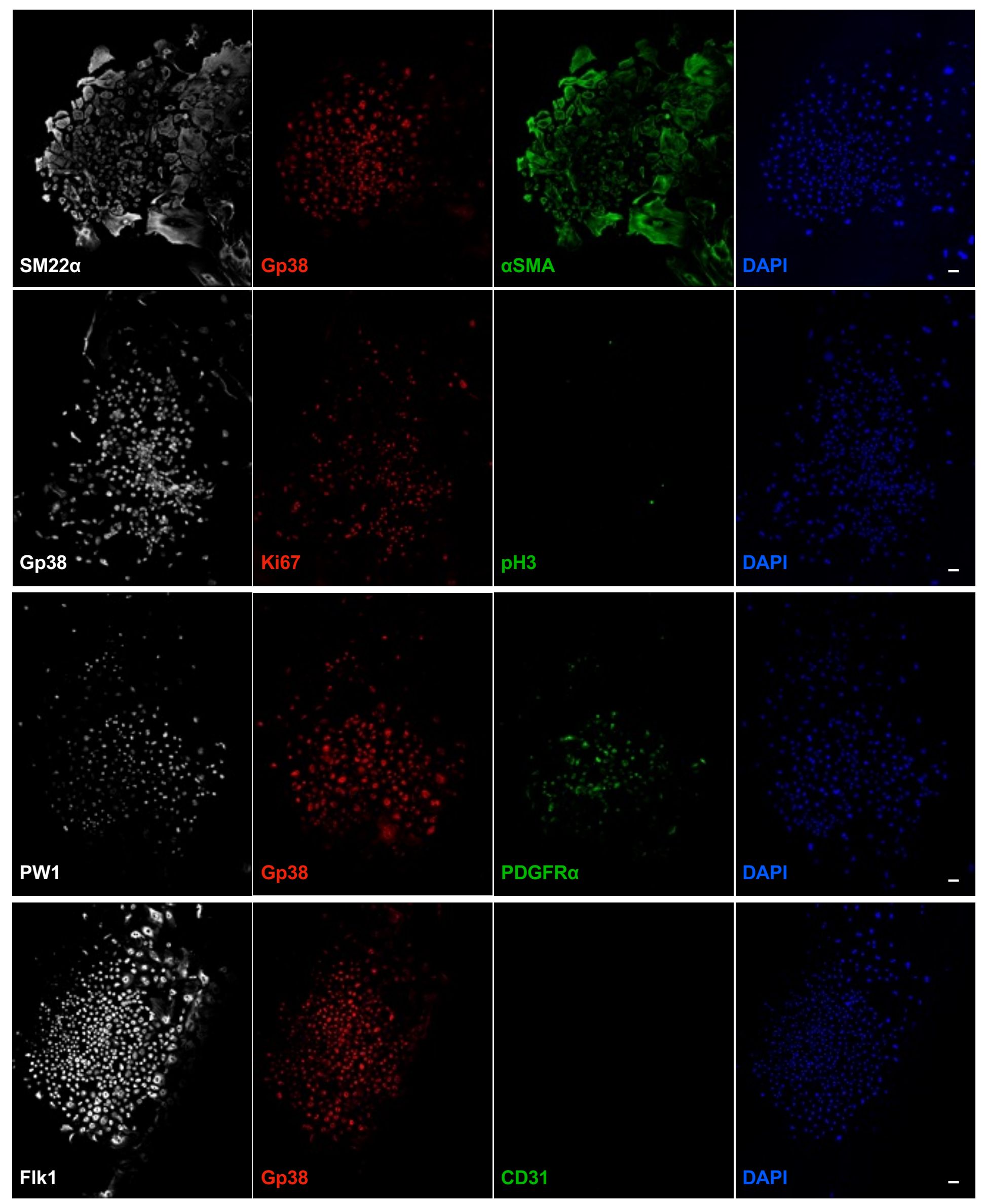

